\title{
Geochemical constraints on the temperature and timing of carbonate formation and lithification in the Nankai Trough, NanTroSEIZE transect
}

\author{
James C. Sample ${ }^{1}$, Marta E. Torres ${ }^{2}$, Andrew Fisher ${ }^{1}$, Wei-Li Hong ${ }^{2}$, Christine \\ Destrigneville $^{3}$, William F. Defliese ${ }^{4}$, and Aradhna E. Tripati ${ }^{4,5,6}$
}

\begin{abstract}
Information about diagenetic processes and temperatures during burial of sediments entering the subduction zone is important for understanding changes in physical properties and seismic behavior during deformation. The geochemistry of authigenic carbonates from accretionary prisms can serve as proxies for conditions during carbonate cementation and resultant lithification. We report results from the Nankai accretionary prism recovered from Integrated Ocean Drilling Program (IODP) Sites C0011 and C0012 and we document continued cementation of deep sediment sections prior to subduction. Elemental and isotope data provide evidence for complex mixing of different isotopic reservoirs in pore waters contributing to carbonate chemical signatures. Carbon stable isotope values exhibit a broad range $\left(\delta^{13} \mathrm{C}_{\mathrm{V}-\mathrm{PDB}}=+0.1\right.$ to $-22.5 \%$ ) that corresponds to different stages of cement formation during burial. Carbonate formation temperatures from carbonate-clumped isotope geochemistry range from $16^{\circ}$ to $63^{\circ} \mathrm{C}$ at Site $\mathrm{C} 0011$ and $8.7^{\circ}$ to $68^{\circ} \mathrm{C}$ at Site $\mathrm{C} 0012$. The correspondence between the clumped-isotope temperatures and extrapolations of measured in situ temperatures indicate the carbonate is continuing to form at present. Calculated water
\end{abstract}


37 isotopic compositions are in some cases enriched in ${ }^{18} \mathrm{O}$ relative to measured interstitial waters suggesting a component of inherited seawater or input from clay-bound water. Low oxygen isotope values and the observed $\mathrm{Ba} / \mathrm{Ca}$ ratios are also consistent with carbonate cementation at depth. Strontium isotopes of interstitial waters $\left({ }^{87} \mathrm{Sr} /{ }^{86} \mathrm{Sr}\right.$ of 0.7059 to 0.7069$)$ and carbonates $\left({ }^{87} \mathrm{Sr} /{ }^{86} \mathrm{Sr}\right.$ of 0.70715 to 0.70891$)$ support formation of carbonates from a mixture of strontium reservoirs including current interstitial waters and relic seawater contemporaneous with deposition. Collectively our data reflect mixed sources of dissolved inorganic carbon and cations that include authigenic phases driven by organic carbon and volcanic alteration reactions. Physical properties of input sediments continue to undergo modification by carbonate cementation at present. Due to ongoing recrystallization, temperatures from carbonate-clumped isotopes reflect the modern geothermal gradient and may serve as useful measures of geothermal gradients in other siliciclastic basins where carbonate cementation occurs. We conclude that clumped-isotope signatures in authigenic carbonates from accretionary prisms are important proxies for the timing and conditions of cementation in active margins. Our results highlight the importance of using multi-proxy approaches to elucidate the history of carbonate cementation, particularly to establish carbonate precipitation at depth and its potential impact on the physical and mechanical properties of the sediment prior to subduction.

\section{Introduction}

The study presented here is part of the larger NanTroSEIZE (Nankai Trough Seismogenic Zone Experiment) Project to characterize inputs and deformation at a margin known for large, historical earthquakes and related tsunami generation (Tobin et al., 2009). Our results characterize sediment inputs in the Shikoku Basin (Fig. 1) and provide a baseline for comparison as the inputs evolve during deformation. Of particular importance are the mineralogy and physical properties of the sediments that can potentially become the focus of concentrated shear along major faults. Physical properties are related to lithology (including clay mineralogy), degree of lithification (cementation, compaction, consolidation), fluid content and fluid pressure (Moore and Saffer, 2001; Saffer and Tobin, 2011; Saffer and Wallace, 2015). Unlithified sediments high in smectitic clay minerals may release accumulated stress by slow slip and seismic tremor. Lithified sediments are more likely to store larger stresses before rupture and thus generate large, hazardous earthquakes (Saffer and Wallace, 2015).

Authigenic carbonate is known to form in marine sediments when diagenetic reactions result in supersaturation of carbonate minerals, and constitutes a significant component of the global carbon inventories (Wallmann et al., 2008; Wehrmann et al., 2013; 
Schrag et al., 2013). Authigenic carbonates are produced from early reactions associated with organic matter decomposition via sulfate, manganese, and iron reduction, and as methane-derived carbonates from anaerobic oxidation of methane (AOM). For example, carbonates recovered from cold seeps on the Nankai accretionary wedge have strongly depleted $\delta^{13} \mathrm{C}$ ratios (-36\% to $-56 \%$ V-PDB; Vienna PeeDee belemnite), suggesting that a component of the carbon was derived from AOM (Sakai et al., 1992). In this and other accretionary wedges, carbonates recovered at greater burial depths commonly retain chemical and isotopic information of the shallow sediments in which they were formed as a product of carbon cycling reactions. Here we document that carbonate cementation may also be occurring deep enough in the sediment sections that it may impact the seismogenic behavior along the plate boundary.

Alteration of sediment along continental margins leads to carbonate formation by a reaction transforming reactive silicates and volcanic ash to clay minerals, and releasing calcium, silica, other cations, and bicarbonate to the pore fluids (Wallmann et al., 2008; Wehrmann et al., 2013; Solomon et al., 2014). Formation of carbonate minerals driven by submarine silicate weathering can consume up to a third of buried carbon at continental margins, and may be as significant in sequestering $\mathrm{CO}_{2}$ as weathering on land (Wallmann et al., 2008). This process is also occurring in the Shikoku Basin, where unstable volcanic matter is abundant (Figs. 1 and 2; Saito et al., 2010; Henry et al., 2012). In the Nankai input sites an additional source of calcium supplied by diffusion from the underlying oceanic basement further supersaturates formation fluids with respect to calcite.

We explore the amount, timing, chemical conditions, and temperatures related to cementation in the incoming sedimentary section of the Shikoku Basin before it enters the zone of megathrusting in the Nankai Trough subduction system. We use the mineralogy and geochemistry of carbonate minerals and interstitial waters, including traditional and carbonate clumped isotope analysis, to document that alteration of volcaniclastic material below the sulfate-methane transition zone (SMTZ) leads to formation of significant authigenic carbonate deep within the sediment column. As such, we provide the first evidence of carbon sequestration in deep-seated carbonate cements, which are partially triggered by weathering of volcaniclastic sediment below the SMTZ. We will show how carbonate-clumped isotope temperatures (Eiler, 2007) can help to constrain the timing of carbonate formation, and provide evidence that the carbonate clumped isotope composition of these carbonates may act as a proxy for the modern geotherm. We show small but significant degrees of carbonate cementation, which if continuing during burial can significantly strengthen the sediment (Sample, 1990). In addition, direct borehole measurements of temperature, together with clumped isotope measurements, provide a 
109 direct constraint on which clumped isotope temperature calibration is most reasonable for 110 the Nankai Trough input sites. Finally, we will discuss how these results are important for 111 contributing to our understanding of fault behavior within the deep accretionary prism, the

112 target of future drilling. Our study focuses on a major convergent margin, but the results may

113 be applicable to other siliciclastic-dominated sedimentary basin where carbonate cements

114 are forming, including petroleum provinces and passive margins.

115

\section{2. Overview of Drilled Sites}

117 Sites C0011 and C0012 (IODP Expeditions 322 and 333) were drilled in the Shikoku

118 Basin to characterize the incoming sedimentary section, 21 and $30 \mathrm{~km}$ southeast of the

119 deformation front, respectively (Fig. 1). The sites share similar sedimentary lithologies. The

120 dominant sediments are bioturbated, fine-grained muds and silts and their lithified

121 equivalents, locally with intervals of abundant volcanic ash or volcaniclastic sediment layers

122 (Fig. 2). The sedimentary section at Site C0011 on the flank of Kashinosaki Knoll is nearly

123 double the thickness found at C0012, at the knoll's crest (Saito et al., 2010; Henry et al.,

124 2012). Lithologic units have been correlated between the two sites. Lithologic Unit I ( 7.6 to

$1257.8 \mathrm{Ma}$ at its base) includes numerous beds of reworked volcanic ash. Ash in Unit IB shows

126 evidence of significant alteration at Site C0011 (Henry et al., 2012; Joseph et al., 2013a).

127 Unit II is 9.1 to $9.4 \mathrm{Ma}$ at its base, and along with hemipelagic mudstone contains volcanic

128 sediment in the form of tuffaceous and volcaniclastic sandstone. Unit III is hemipelagic

129 mudstone ranging from $\sim 9.1$ to $12.5 \mathrm{Ma}$ in age and is relatively free of volcanic input. Unit IV

130 comprises dominantly mudstones and siltstones. Sandy turbidites present in Unit IV at Site

131 C0011 are not found at C0012. The lack of this more permeable lithology may serve to

132 hydrologically isolate C0012 from subsurface fluids expelled at the deformation front,

133 because at C0012 there is not a permeable pathway for fluid flow (Saito et al., 2010). Unit V

134 is the deepest unit at C0011 and only the upper portion was cored due to failure of the drill

135 bit. Sediment recovered from Unit $V$ at Site C0011 contains volcanic ash layers. These ash

136 layers are also observed in Unit $\mathrm{V}$ at $\mathrm{C} 0012$, which in addition contains abundant siliciclastic

137 and volcaniclastic sandstone layers. The oldest sediment cored at C0011 is >14.0 Ma.

138 Drilling at C0012 penetrated to basement and includes an additional unit (VI) comprising

139 calcareous claystone. The sediment-basement contact was cored in numerous holes and

140 yielded an age based on nannofossils of $>18.9 \mathrm{Ma}$. Abundant smectite in the Shikoku Basin

141 sediments is indicative of alteration products of volcanic glass (Saito et al., 2010; Henry et

142 al., 2012), an alteration that may play a role in formation of diagenetic carbonate during

143 burial. 
$145 \mathrm{C} 0011$ and $4.4 \mathrm{wt} \%$ at Site C0012; carbonate abundances between 10 and $20 \mathrm{wt} \%$ are

146 common in layers (Fig. 1; Expedition 322 Scientists, 2010ab; Expedition 333 Scientists,

147 2012ab). Carbonate is most abundant in approximately the upper third of the sections, with

148 the exception of high carbonate abundances in the calcareous claystone at the base of Site

149 C0012. Deposition of most sediment in deep water results in poor preservation of calcareous

150 nannofossils and makes it highly probable that a large fraction of the carbonate in the cores

151 formed through diagenetic reactions.

152

\section{3. Methods}

154 We used a combination of mineralogical and geochemical methods to explore

155 characteristics of carbonate and interstitial water. Summarized here are the methods used

156 for post-expedition analyses.

157

158 3.1. X-ray diffraction (XRD).

159 Carbonate mineralogy and abundance in 75 samples from Sites C0011 and C0012 160 were analyzed using a Siemens D500 diffractrometer at Northern Arizona University (NAU;

161 Appendix), at $43 \mathrm{kV}$ and 38 amps. Runs were conducted at a step of $0.01^{\circ} 2 \Theta$ and dwell time

162 of $1 \mathrm{~s}$. Peak heights for the main carbonate peaks were compared to in-house standards

163 comprising powdered, acid-leached shale mixed with known amounts of calcite (Appendix).

$164 \mathrm{XRD}$ is an efficient method for characterizing the bulk mineralogy of small sample sizes, but

165 carbonate abundances obtained from this method have significant uncertainty, especially at

166 low carbonate concentration (Expedition 348 Scientists, 2015a), and results presented here

167 are considered semi-quantitative measures of relative abundances of different carbonate 168 phases.

3.2. Scanning electron microscopy and electron probe microanalysis.

171 Fifteen samples were chosen for scanning electron microscopy (SEM) and electron 172 probe microanalysis (EPMA) analyses at NAU. The SEM is a JEOL 6480LV with

173 backscattered electron detector (BSED) and Oxford energy-dispersive X-ray analysis

174 system (EDS) used to determine semi-quantitative elemental compositions. EPMA used a

175 Cameca SX-50 microprobe with beam current of $10 \mathrm{amps}$, voltage at $15 \mathrm{kV}$, and a wide

176 beam to minimize mineral damage. Carbonate standards were calcite, dolomite, siderite,

177 rhodochrosite, and strontianite (Appendix). Chemical analyses by EPMA yield values

178 accurate to within $\sim 1-2$ wt\% relative.

179 
182 Bench II automated sampler interfaced to a gas source stable isotope mass spectrometer at 183 Oregon State University (OSU) as described in Torres et al. (2005). DIC is allowed to evolve 184 as $\mathrm{CO}_{2}$ by addition of $\mathrm{H}_{3} \mathrm{PO}_{4}$, and a known volume of dry $\mathrm{CO}_{2}$ is transferred to a Finnigan 185 DELTAplusXL mass spectrometer, which integrates the relevant isotope masses $(\mathrm{m} / \mathrm{z}=44$, 18645 , and 46) as the $\mathrm{CO}_{2}$ peak enters the source. The precision of the $\delta^{13} \mathrm{C}$ measurements 187 based on replicate analyses of a $\mathrm{NaHCO}_{3}$ stock solution is better than $\pm 0.1 \%$.

At Institut de Physique du Globe de Paris, the oxygen isotope compositions of fluid samples were measured using a GC-IRMS (AP2003) after equilibration of an aliquot (0.8

$190 \mathrm{~mL}$ ) of water sample with a $\mathrm{He}+\mathrm{CO}_{2}$ gas mixture. The measurements were calibrated using

191 a set of water standards to provide $\delta^{18} O$ versus the V-SMOW (Vienna Standard Mean

192 Ocean Water) standard scale. Measurements of $\delta^{18} \mathrm{O}$ were determined with an analytical 193 accuracy of better than $\pm 0.1 \%$.

\subsection{Carbonate elemental and isotope geochemistry}

For samples analyzed for elemental ratios, $10 \mathrm{mg}$ of powdered sample were weighed and transferred into an acid-clean Teflon vial, to which $3 \mathrm{~mL}$ of $4 \mathrm{~N} \mathrm{HNO}_{3}$ was added to dissolve the carbonate. An additional $3 \mathrm{~mL}$ of $4 \mathrm{~N} \mathrm{HNO}_{3}$ was added if the original volume failed to dissolve the whole carbonate component of the sample. Acidified samples were then centrifuged and prepared for ICP-OES analysis at OSU. Calibration was done against a series of mixed standards containing $\mathrm{Ca}, \mathrm{Mg}, \mathrm{Sr}, \mathrm{Mn}$, and $\mathrm{Ba}$ in ratios expected for methane-derived carbonates (e.g., Bayon et al., 2007; Torres et al., 2010). In addition, an aliquot of each sample was measured for Al to identify potential silicate contamination during acidification. Clay mineral contamination was less than $5 \%$ of the measured value in all samples.

For strontium isotope analyses, $10 \mathrm{mg}$ of powdered sample was placed in an acidwashed Teflon vial and acidified with $4 \mathrm{~mL}$ of $25 \%(4 \mathrm{~N}) \mathrm{CH}_{3} \mathrm{COOH}$. An additional $4 \mathrm{~mL}$ of $25 \% \mathrm{CH}_{3} \mathrm{COOH}$ was added if the initial volume failed to dissolve the whole sample. This solution was then refluxed at $70{ }^{\circ} \mathrm{C}$ for $12 \mathrm{~h}$, sonicated for $30 \mathrm{~min}$, centrifuged and decanted into Teflon vials. Strontium separation was carried out using a $50 \mu \mathrm{L} \mathrm{Sr-specific} \mathrm{column}$ and resin from EICHROM. Isotopic analysis of a solution containing $300 \mathrm{ng} \mathrm{Sr}$ was

213 ICPMS) housed in the W.M. Keck Co-laboratory for Plasma Spectrometry in the College of 214 Oceanic and Atmospheric Science at OSU. ${ }^{87} \mathrm{Sr} /{ }^{86} \mathrm{Sr}$ data were normalized to NIST standard 215 NBS 987, with a reported ${ }^{87} \mathrm{Sr} /{ }^{86} \mathrm{Sr}$ value of 0.710245 (Table 1; Joseph et al., 2013a). A 
216 mean value of $0.710225 \pm 0.000052(2 \sigma$ mean; $n=91)$ was obtained for repeated 217 measurements. Replicate analysis of an in-house standard yielded a ${ }^{87} \mathrm{Sr} /{ }^{86} \mathrm{Sr}$ ratio of $2180.708170 \pm 0.000051(2 \sigma$ mean; $n=79)$.

219 Samples selected for carbon and oxygen isotope analyses at NAU were powdered in 220 a synthetic sapphire mortar and pestle and weighed into Labco Exetainer® vials for a target 221 mass of 250 micrograms of carbonate per sample. Samples were purged with helium and 222 reacted with $103 \%$ phosphoric acid for $\sim 1$ hour at $70^{\circ} \mathrm{C}$, and the $\mathrm{CO}_{2}$ gas was introduced 223 with a helium carrier to a Finnigan Gasbench II where it is separated from water vapor and $224 \mathrm{~N}_{2} \mathrm{O}$ gas. Masses 44,45 , and 46 were then measured with a Finnigan Delta Plus isotope225 ratio mass spectrometer in the NAU Colorado Plateau Stable Isotope Laboratory. $\delta^{13} \mathrm{C}$ data 226 were normalized using NBS-18, NBS-19 and LSVEC standards. $\delta^{18} \mathrm{O}$ data were normalized 227 using NBS-18 and NBS-19 standards. Analytical uncertainties are typically less than $\pm 0.1 \%$ 228 for $\delta^{18} \mathrm{O}$ and $\delta^{13} \mathrm{C}(1 \sigma)$. where $\mathrm{R}$ refers to the ratio of the minor isotopologue to the major isotopologue of the molecule (or atom) of interest (Eiler and Schauble, 2004). $\Delta_{47}$ measurements were made on 10 samples each from sites $\mathrm{C} 0011$ and $\mathrm{C} 0012$ using three different mass spectrometers with similar results: a specially modified Thermo Fisher MAT 253 gas source mass spectrometer and a Nu Perspective IS in the Tripati Lab at the University of California, Los

240 Angeles (UCLA); and a Thermo Fisher MAT 253 mass spectrometer at Caltech (Table 2). A

241 brief description of the procedures is below and a more in-depth description is published 242 elsewhere (Huntington et al., 2009; Passey et al., 2010; Tripati et al., 2010; Loyd et al., 243 2012).

244 Sample and standards were processed using custom-built automated systems for digestion and purification attached to each gas source mass spectrometer that has been configured for the analysis of multiply substituted isotopologues of $\mathrm{CO}_{2}$ (after Passey et al., 2010). The carbonate sample digestion system is composed of 1 ) a stainless steel autosampler that will hold high vacuum, 2) a common acid bath for phosphoric acid digestion

249 of samples, 3) cryogenic traps (dry ice and ethanol, and liquid nitrogen) for the purification 
and collection of $\mathrm{CO}_{2}$ and removal of water and other gases with low vapor pressures, 4) a gas chromatograph with a packed column and a cryogenic trap to further purify $\mathrm{CO}_{2}$ through the removal of organic contaminants, with helium being used as a carrier gas, with a flow rate of $\sim 25 \mathrm{~mL} / \mathrm{min}, 5$ ) cryogenic traps to separate prepared gases from the helium, 6) a final set of valves and traps to purify $\mathrm{CO}_{2}$ and transfer it into the bellows of the mass spectrometer. In this system, powdered samples with a carbonate mass of $8 \mathrm{mg}$ are digested at $90^{\circ} \mathrm{C}$ in phosphoric acid ( $\rho=1.94 \mathrm{~g} / \mathrm{ml} ; 105 \mathrm{wt} \%$ ) in order to ensure a sufficient amount of $\mathrm{CO}_{2}$ for stable voltages over the course of several hours. The reaction time was 20 minutes in a common acid bath system, with acid changed after every 10-15 analyses. Most samples were calcite or calcite with minor dolomite or rhododchrosite-siderite (R-S). There are four samples with the highest abundances of dolomite plus siderite range over 40$85 \mathrm{wt} \%$ of these phases. Twenty minutes has been shown to be sufficient reaction time for dolomite (Defliese et al., 2016). A previous study of clumped isotopes of siderite used longer reaction times (Fernandez et al., 2014), but to our knowledge no studies have been done on the R-S solid-solution. The R-S occurrences are typically as small, widely disseminated crystals 1-5 $\mu \mathrm{m}$ (Fig. 3) that are likely to dissolve rapidly, but it is uncertain if complete dissolution of the R-S phase occurred. There is no evidence for artefacts in the data related to partial dissolution, since with only one exception, the results from the four high R-S samples do not differ significantly from calcite-dominated samples nearby in depth. A geological explanation for the exceptional sample is presented in the Discussion section.

The resultant gas from the acid bath was immediately sent through a glass water trap immersed in a dewar of ethanol/dry ice at $-70^{\circ} \mathrm{C}$, and $\mathrm{CO}_{2}$ frozen in a second metal trap immersed in a dewar of liquid nitrogen. After two rounds of cryogenic purification to remove water, $\mathrm{CO}_{2}$ is then passed through a gas chromatograph containing a column filled with

274 PoraPak $Q$ that is at $-20^{\circ} \mathrm{C}$, and then recleaned cryogenically as described above to remove 275 any additional water before being transferred to the inlet of the mass spectrometer. Measurements are made to yield a stable 16-volt signal for mass 44, with peak centering, background measurement, and pressure balancing before each acquisition.

At UCLA, an "absolute reference frame" (ARF) was developed by analyzing $\mathrm{CO}_{2}$ gas with different bulk isotope compositions equilibrated at multiple temperatures, and combined with carbonate standards to construct a secondary transfer function (Dennis et al., 2011). At Caltech, data were transferred to the ARF by use of two carbonate standards (Carrara Marble and TV01) and the use of a $1000^{\circ} \mathrm{C}$ equilibrated gas line, similar to prior studies where two equilibrated gas lines were not established (Dennis et al., 2011). Equilibrated gases are prepared at $25^{\circ} \mathrm{C}$ by exchange with $\mathrm{H}_{2} \mathrm{O}$, and at $1000^{\circ} \mathrm{C}$ by sealing in a quartz tube and heating in an oven for a minimum of two hours, followed by quenching at room 
temperature. Standard gases are then purified and analyzed using the same protocol as sample gases. Approximately two to eight sample analyses and a minimum of three standard analyses (both gas standards and carbonate standards) were performed each day, depending on instrumentation. All carbonate data use the Henkes et al. (2013) acid

290 digestion fractionation factor of $0.092 \%$, that was generated on the same type of

291 instrumentation as ours, to normalize to $25^{\circ} \mathrm{C}$; Defliese et al. (2015) report an acid digestion

292 fractionation factor for $\Delta_{47}$ of 0.082 per mil at 90 deg. C, with an error of $+/-0.014$ per mil (2

293 standard deviations) that is statistically identical to the value from Henkes et al. (2013). Both 294 papers use a common acid bath system for the $90^{\circ} \mathrm{C}$ reactions, which justifies the choice of 295 fractionation factor.

All $\Delta_{47}$ data in tables and figures are reported on the absolute reference frame.

297 Uncertainties in reported $\Delta_{47}$ values and calculated temperatures include the propagated

298 uncertainty in equilibrated gas determination and in sample measurement (Huntington, et al., 299 2009).

At UCLA we repeatedly ran a Carmel Chalk standard and determined an average $\Delta_{47}$ value of $0.683 \pm 0.005 \%$ ( 1 s.e.) at UCLA (compared to a nominal value of $0.697 \%$ o based on analyses by Tripati at Caltech), a Carrara Marble standard with a value of $0.397 \pm 0.009 \%$ (1 s.e.) (compared to a measured value of $0.397 \%$ from analyses at Caltech), and a TV01 standard with a value of $0.720 \%$ \pm 0.012 ( 1 s.e.) (compared to a value of $0.713 \%$ measured at Caltech).

Precision over the two months that analyses were made for this project, as

308 other studies (Eiler, 2007; Huntington et al., 2009; Eagle et al., 2010, 2011, 2013; Tripati et 309 al., 2010; Thiagarajan et al., 2011; Rosenheim et al., 2013). For analyses with more than 310 one replicate all errors are based on external error. For a single replicate, the error is based on internal error. In order to monitor the presence of clean $\mathrm{CO}_{2}$ samples, we screened for

312 the presence of contaminating molecules such as hydrocarbons and sulfur compounds 313 using mass 48 anomalies.

Temperatures are calculated using a published calibration equation (Tripati et al., 315 2015) for inorganic calcite data that was recalculated on the absolute reference frame 316 (Dennis et al., 2011). This temperature calibration was generated using the same 317 instrumental set-up as used for the measurement of samples in this study. The uncertainty in 318 temperature includes the standard error for individual measurements and the standard error 319 between replicate analyses. Similar temperature results are obtained using the calibration of 320 Ghosh et al. (2006). Other calibrations (Tang et al., 2014; Kluge et al., 2015; Defliese et al., 2015) yield high temperatures of formation relative to the modern geothermal gradient. All 
322 temperature calibrations are calculated or re-calculated using a $25-90{ }^{\circ} \mathrm{C}$ acid fractionation

323 factor of $0.092 \%$, identical to what was used in this study, and calibration equations and

324 temperature calculations are provided in the Appendix.

325 The uncertainty in calculated water isotopic composition includes the internal error in 326 temperature measurements for single replicates or external error for multiple replicates, and 327 the uncertainty in measured $\delta^{18} \mathrm{O}$ values of carbonates.

\section{Results}

We present mineralogical, textural, and geochemical data from secondary carbonates found in both input sites, which are compared to chemical data from interstitial waters (IW). The results place constraints on mechanisms and relative timing of formation of secondary carbonates.

4.1. Diagenetic carbonate textures and element chemistry.

Multiple mineralogical phases of carbonate are found in input sites C0011 and C0012. Evidence presented below suggests carbonate precipitated over a prolonged burial history. Carbonate abundances in samples for the present study range from 2.1 to $15.4 \mathrm{wt} \%$, with two outliers of $36.7 \mathrm{wt} \%$ and $83.6 \mathrm{wt} \%$ (Appendix). There is no downhole trend of abundance in our samples for either site. High abundances are also found in pelagic calcareous claystone at the base of the sedimentary section in C0012 (Figs. 1 and 2).

We analyzed mineral and elemental compositions of carbonates to understand the mechanisms of cement formation and post-depositional alteration associated with the 344 carbonate record (e.g. Pingitore, 1978; Veizer, 1983; Tucker et al., 1990; Bayon, 2007). 345 Calcite is the most abundant carbonate cement, found in 67 of 75 samples examined. It is 346 the dominant carbonate in two-thirds of the samples (Appendix). XRD patterns show a shift 347 to higher values of the primary calcite peak from $29.4^{\circ} 2 \Theta$ in several samples. Typically the 348 shift has been attributed to substitution of $\mathrm{MgO}$ for $\mathrm{CaO}$ in the calcite structure. But microprobe analyses of selected samples in our study shows $\mathrm{MnO}$ substitution and to a lesser degree $\mathrm{FeO}$ substitution in calcite is most commonly responsible for the shift (Appendix). Average $\mathrm{MnO}$ concentrations in main calcite cements are 3.6 to $13.2 \mathrm{wt} \%$. In the rest of the paper we refer to calcites and Mn-calcites together as calcites.

The second most common carbonate phase is represented by a solid solution

354 between rhodochrosite and siderite (Appendix; hereafter designated as "R-S"), which can be 355 identified by one or more peaks between $\sim 31.5^{\circ}$ and $32.0^{\circ} 2 \Theta$. The primary peak locations 356 for rhodochrosite and siderite are $31.45^{\circ}$ and $32.00^{\circ} 2 \Theta$, respectively. Evidence for R-S is 357 found in 41 samples, and it is the dominant carbonate in 11 samples; only one of the latter 
was analyzed for clumped isotopes. The phase is typically too small to analyze with the microprobe (Figs. 3 and 4); the compositions of three samples are summarized in the Appendix. R-S also contains small amounts of MgO. Dolomite is present in 9 of 75 samples examined and dominant in only four. Siderite is a rare phase locally associated with pyrite. Textural evidence provides evidence of co-precipitation of calcite and R-S. Calcite typically occurs as 20-50 micrometer ellipsoidal clots in a matrix of clay minerals (Fig. 3). Small $(<5 \mu \mathrm{m})$ crystals of isolated, idiomorphic R-S, and locally quartz, also occur in the larger calcite clots. Both calcite and R-S also are dispersed as small crystals in the clay matrix. The cores of R-S crystals in the matrix may be partially dissolved to develop secondary porosity. In other samples both calcite and R-S partially replace volcanic ash shards (Fig. 3). These textures suggest that calcite and R-S crystallized together. The trace element chemistry indicates manganese and iron were readily available in reduced form in pore waters during neocrystallization or recrystallization of carbonates. Dolomite was not found in situ by SEM, and its relationship to other authigenic phases is unclear.

There are no apparent trends in mineralogy with depth (Figs. 5 and 6). At C0011 calcite dominates the assemblages at all levels. R-S becomes increasingly common below 400 mbsf, as a nearly pure phase or as a minor phase with calcite. The R-S at depth may be a relict of carbonate formed at shallower depths (see section 4.2.1 below). At $\mathrm{C} 0012$ the pattern is reversed; R-S is more abundant in the upper $200 \mathrm{~m}$ of the section. In addition at this site dolomite is more common, but it is largely confined to an interval between 140 and 230 mbsf.

The $\mathrm{Ba} / \mathrm{Ca}$ and $\mathrm{Mn} / \mathrm{Ca}$ ratios for bulk leachates of carbonates and interstitial water concentrations are shown in Figure 7. The $\mathrm{Ba} / \mathrm{Ca}$ ratio varies widely, both down-core and between sites. Barium incorporation into carbonate minerals is dependent upon barium availability in IW. The main source of dissolved barium in pore fluids is through dissolution of barite (Torres et al., 1996). Because barite dissolution occurs below the zone of sulfate depletion, high $\mathrm{Ba} / \mathrm{Ca}$ levels in the carbonates indicate cement formation was below the SMTZ. The high abundance of manganese in carbonates is expected given the high concentrations of reduced manganese observed in interstitial waters. The availability of manganese likely results from alteration of volcanic matter, and reduction via active sulfur cycling by a microbial community (Torres et al., 2015). High abundance of Mn-bearing calcites is consistent with the observed $\mathrm{Mn} / \mathrm{Ca}$ ratios in IW. It is notable that the trends in manganese concentrations are similar in carbonate and IW at Site C0012 from depths of 322 to $475 \mathrm{mbsf}$ and may provide evidence of recent crystallization of these carbonates below the SMTZ (Fig. 7). 


\subsection{Carbonate isotope geochemistry}

Carbon, oxygen, strontium, and clumped isotopes of carbonates are compared with modern interstitial water (IW) values to assess the degree of equilibrium between solid and fluid phases, and the conditions of carbonate formation.

\subsubsection{Light stable isotopes $\left(\delta^{13} \mathrm{C}, \delta^{18} \mathrm{O}\right.$, and carbonate-clumped isotopes)}

Stable isotope data indicate processes of carbonate precipitation, the temperature during precipitation, evolving isotopic compositions of the IW, and carbon cycling in the Shikoku Basin. Carbonate stable isotopes in the Shikoku Basin span a broad range from values expected of typical marine carbonates to those strongly depleted in ${ }^{13} \mathrm{C}$ and ${ }^{18} \mathrm{O}$ (Table 1; Figs. 5 and 6). The two Shikoku Basin input sites share some attributes. Both have a shallow population of samples with the least depleted isotopic ratios for carbon and oxygen in Lithologic Unit I. A deeper population of carbonates generally is more isotopically depleted.

\subsubsection{Site C0011}

At Site $\mathrm{C} 0011$ strong ${ }^{13} \mathrm{C}$ and ${ }^{18} \mathrm{O}$ depletions begin below $400 \mathrm{mbsf}$ in Lithologic Unit II (Fig. 5). $\delta^{18} \mathrm{O}$ and $\delta^{13} \mathrm{C}$ values range as low as $-11.9 \%$ and $-23.4 \%$, respectively. Although scattered, $\delta^{18} \mathrm{O}$ generally shows a decrease in minimum values with depth. The oxygen isotope values could result from a combination of inputs from seawater, IW modified by water-rock interactions and alteration of sediment, and increasing temperature during burial. The samples strongly depleted in ${ }^{18} \mathrm{O}$ and ${ }^{13} \mathrm{C}$ require carbonate formation after significant modifications to seawater chemistry and possibly increased temperatures. The carbon isotopes of carbonates have a broad range of values that are lighter than dissolved inorganic carbon (DIC). With only a few exceptions in lithologic Unit IV, carbonates and DIC are not in equilibrium (Fig. 5).

Carbonate clumped isotope data provide quantitative measures of temperature and inferred $\delta^{18} \mathrm{O}$ values of pore waters during carbonate formation. Samples with the greatest ${ }^{18} \mathrm{O}$ depletions were chosen for clumped isotope analysis;, five samples with $\delta^{18} \mathrm{O}$ values > $1 \%$ were also analyzed (Table 2; Fig. 5). For the calculated temperatures we used the temperature calibration of Tripati et al. (2015). Temperature calculations for other calibrations are also shown in the Appendix. Four analyzed samples are calcite with some $\mathrm{MnO}$ substitution, four are dominantly calcite with significant $\mathrm{R}-\mathrm{S}$, and one is a 50:50 mixture of calcite and R-S. We were unable to target individual carbonate phases and generations for analysis due to the dispersed nature of cement within the samples. Direct evaluation of mineralogical effects on clumped isotope temperatures and possible mixing relationships 
430 (Defliese and Lohmann, 2015) therefore is not possible, but the temperatures of bulk

431 samples do not show any systematic dependence on mineralogy.

432 The modern geotherm is shown for comparison with carbonate-clumped

433 temperatures (Fig. 5). Generally clumped-isotope temperatures at C0011 lie very close to

434 the geotherm, regardless of mineralogy. This is true even for three samples relatively

435 undepleted in ${ }^{18} \mathrm{O}$ at 125, 250, and 269 mbsf. Three samples between $\sim 600-700$ mbsf plot

436 significantly to the left of the geotherm. These include calcites with 13-22 wt\% R-S, and one

437 R-S with 15 wt\% calcite. The temperatures lower than the geotherm could result from partial

438 preservation of early-formed carbonate cement formed at shallower depths and subsequent

439 burial. In general, however, the clumped-isotope results indicate the carbonates formed at

440 temperatures similar to those found at their current depths.

441 The $\delta^{18} \mathrm{O}$ values of fluids $\mathrm{C} 0011$ derived from clumped temperatures and inferred to

442 be in equilibrium with the carbonates are shown in Figure 5D. To distinguish these waters

443 from interstitial waters measured from core samples, hereafter we will refer to waters from

444 clumped-isotope analysis as "clumped-water" isotope values. The clumped-water $\delta^{18} \mathrm{O}$

445 values presented here are calculated assuming all carbonate is calcite and using the calcite-

446 water fractionation expression of Kim and O'Neil (1997). The clumped-water isotopic

447 compositions thus derived are heavier than current IW values. The differences range from 0 -

$4485 \%$ heavier within error for most carbonate samples. The actual difference is probably less

449 because the carbonates are not pure calcite. The fractionation between carbonate and water

450 is generally higher for minerals other than calcite, and with increasing substitution of $\mathrm{MgO}$,

$451 \mathrm{MnO}$ or $\mathrm{FeO}$ for $\mathrm{CaO}$ in the calcite structure. Accounting for these differences from pure

452 calcite would lessen the isotopic difference between clumped fluid determinations and

453 sampled interstitial waters. The correction can be as large as $3 \%$ for siderite (Carothers et

454 al., 1988). For the sample dominated by R-S, a clumped-water $\delta^{18} \mathrm{O}$ value corrected using

455 the siderite-water fractionation expression of Carothers et al (1988) is shown in Figure 5.

456 But the isotopic compositions of end-member carbonates are not known, and thus it is not

457 possible to accurately calculate the $\delta^{18} \mathrm{O}$ values of the clumped-fluid isotopic compositions to

458 account for the effects of mixtures of carbonate minerals in all samples. The clumped-

459 derived fluid isotope data are not likely to overlap completely with modern IW $\delta^{18} \mathrm{O}$ values

460 even if corrections were made for trace-element substitutions for $\mathrm{CaO}$.

461

462 4.2.1.2. Site C0012

463

464 The ranges in carbon and oxygen isotopic data at Site C0012 are similar to those at

465 C0011, but show some important differences (Fig. 6). Depletions of heavy isotopes of 
carbon and oxygen begin at different depths. At Site C0012, ${ }^{13} \mathrm{C}$ depletions begin near the base of Lithologic Unit I ( 139 mbsf), but strong ${ }^{18} \mathrm{O}$ depletions are not observed until near the base of Unit III ( 330 mbsf). In the shallow group of carbonates, there is more scatter in $\delta^{18} \mathrm{O}$ values, including a sample at $139 \mathrm{mbsf}$ with the lowest observed $\delta^{18} \mathrm{O}$ value for R-S at either site. The shallow group has the most dolomite-bearing samples, which have the highest oxygen isotope values. High $\delta^{18} \mathrm{O}$ is commonly observed in dolomites forming in shallow carbonate crusts or as dispersed cements in the sediment column at continental margins above the SMTZ, where microbially-mediated carbon cycling occurs (Sample and Reid, 1998; Campbell et al., 2002). As with C0011, at C0012 the deeper population shows the greatest ${ }^{18} \mathrm{O}$ depletions, which occur in the calcite-dominated samples. The carbon isotope values range from slightly to moderately depleted. The carbonate carbon is also not in isotopic equilibrium with DIC carbon, with a few exceptions (Fig. 6). Although values are offset, carbonates in Units IV and V show parallel trends in $\delta^{13} \mathrm{C}$ with DIC carbon.

Drilling at Site C0012 penetrated into basement, and we collected samples of the pelagic carbonate mudstone from just above the basement contact. These appear to retain their original isotopic compositions in carbon and oxygen expected for formation of carbonate tests from seawater. The lowest $\delta^{18} \mathrm{O}$ value in $\mathrm{C} 0012$ was measured in a carbonate vein from the basement, and is the lowest $\delta^{18} \mathrm{O}$ value of all samples analyzed. This sample will not be discussed further.

Clumped isotope measurements define a temperature array that is subparallel to the geotherm at Site C0012. With the exception of the mixed calcite/dolomite sample at 481 mbsf, all sediment samples lie very close to the downhole temperature gradient and are permissive of recent carbonate formation at or near current temperatures. The mixed calcite/dolomite concretion ( $45 \mathrm{wt} \%$ dolomite) yielded a clumped isotope temperature of $8.7^{\circ} \mathrm{C}$ (Table 2; Fig. 6). The temperature is consistent with carbonate formation above the SMTZ, which occurs at $\sim 200 \mathrm{mbsf}$ and coincides with a current temperature of $\sim 30^{\circ} \mathrm{C}$. Even though the thermal gradient at C0012 is significantly higher than C0011, the clumpedisotope temperatures at Site C0012 parallel the modern gradient.

The calculated clumped-water isotopic values for Site C0012 are shown in Figure 6. $\delta^{18} \mathrm{O}$ values range from -5.2 to $4.9 \%$; most are $<0 \%$. As with $\mathrm{C} 0011$ the values for $\mathrm{C} 0012$ are mostly higher than modern IW $\delta^{18} \mathrm{O}$ values. One carbonate sample overlaps the IW values, and six are within $2 \%$. Overall the difference between clumped isotope values and IW is smaller at C0012, which may reflect the greater abundance of calcite in these samples, suggestive of more complete recrystallization. The largest corrections related to mineralogy would result in decreases of 0.5 to $1.0 \%$ in the two dolomite-rich samples, at 147 and 481 mbsf, and the R-S-bearing sample at $69 \mathrm{mbsf}$. The correction shown for the dolomite sample 
502 at 147 mbsf uses the dolomite fractionation expression of Vasconcelos et al. (2005). Even

503 with corrections for mineralogy the clumped-water isotopic compositions would likely still be

504 higher than $\delta^{18} \mathrm{O}$ values of interstitial water. From these data it appears the carbonates did

505 not form in oxygen isotopic equilibrium with current IW at some depths.

506

\subsubsection{Strontium isotopes}

508 Strontium isotopes of carbonates lie between modern interstitial water values and 509 contemporaneous seawater values (Fig. 7). The ${ }^{87} \mathrm{Sr} /{ }^{86} \mathrm{Sr}$ range of carbonates at $\mathrm{C} 0011$ is $510 \quad 0.70777$ to 0.70869 . Over the depth range of analyzed carbonates, IW values exhibit a 511 narrow range of 0.70672 to 0.70693 . A similar pattern of carbonate values intermediate 512 between IW and contemporaneous seawater is also observed at Site C0012, although here 513 there is less scatter in the carbonate data, and IW and carbonate show a subparallel trend of 514 decreasing ${ }^{87} \mathrm{Sr} /{ }^{86} \mathrm{Sr}$ with depth. Comparison of strontium with carbon and oxygen isotopes 515 does not show a trend for either site (Appendix). Overall the results indicate the strontium 516 pool in the diagenetic carbonates is a mixture of strontium from IW and seawater reservoirs.

517 In summary, the Shikoku Basin diagenetic carbonates exhibit variations in barium 518 and manganese concentrations that reflect modern interstitial waters. The lowest $\delta^{18} \mathrm{O}$ 519 values are typically found in calcite-dominated samples. Temperatures from clumped 520 carbonate analysis do not show a dependence on mineralogy. The clumped isotope 521 temperatures are broadly aligned with the modern geotherm at each site, with some 522 exceptions. The $\delta^{18} \mathrm{O}$ values of waters derived from clumped isotope measurements 523 generally are more ${ }^{18} \mathrm{O}$-enriched than modern interstitial waters. Strontium and carbon 524 isotopes of carbonates suggest a mixture of strontium and carbon reservoirs, including a 525 component of interstitial water.

\section{DISCUSSION}

529 Carbonate cementation is an important active process throughout the entire section 530 of Shikoku Basin sediments. The following discussion reconstructs the history of carbonate 531 diagenesis based on geochemical and mineralogical data. The data provide constraints on 532 the carbonate-forming process and have some important implications for characterizing 533 temperature gradients and physical properties of sediments in subduction systems. The role 534 of cementation and its relative depth within a formation determines whether cementation or 535 compaction is the principal driver of porosity reduction. Cements alter the mechanical 536 properties of the sediment, have a significant impact on its permeability, and thus affect fluid 
537 flow. All of these cement-induced changes, especially when they occur at depth, will play a

538 large role in the seismogenic behavior of the margin.

\section{5.1. Timing of carbonate formation}

541 Based on the stable isotopic results the carbonates can be subdivided into two major

542 groups. The upper $300 \mathrm{~m}$ at C0011 and upper 150-200 m at C0012 have characteristics that

543 can best be explained by relatively shallow, early-formed carbonates. Foremost are stable

544 isotope signatures commonly associated with formation in waters that are not significantly

545 different than the initial seawater composition. The decrease in $\delta^{13} \mathrm{C}$ values beginning at 150

546 mbsf may correspond to ${ }^{13} \mathrm{C}$-depleted carbonates forming just above the sulfate-methane

547 transition zone (SMTZ), which is at 200 mbsf (Fig. 6; Whiticar, 1999). Samples with

548 combined calcite, dolomite, and R-S with these shallow isotopic characteristics is consistent

549 with textural evidence of co-preciptation, and indicates most of the carbonates are

550 diagenetic cements rather than carbonate tests from hemipelagic sedimentation. The

551 second, deeper group is characterized by decreases in $\delta^{18} \mathrm{O}$ and $\delta^{13} \mathrm{C}$ values with depth. The

552 steady decrease of $\delta^{18} \mathrm{O}$ may result from a combination of increasing temperature and locally

553 enhanced rates of alteration of volcanic matter to smectite at both sites (see below). The

554 greater scatter in the deep group suggests some samples retain an early, undepleted $\delta^{18} \mathrm{O}$

555 signature. A persistent ${ }^{13} \mathrm{C}$ depletion in the deeper group is expected for input of light carbon

556 derived from the sulfate-reduction process above the sulfate-methane transition zone

557 (SMTZ). Lowered values of ${ }^{87} \mathrm{Sr} /{ }^{86} \mathrm{Sr}$ in carbonates relative to contemporaneous seawater

558 values present at the time of deposition in sites C0011 and C0012 at 600 mbsf and 200

559 mbsf, respectively, are consistent with input from the strontium reservoir derived from

560 alteration of sedimentary volcanic matter (Fig. 7; Joseph et al., 2013a).

561 The carbonate clumped isotope data provide an important constraint on the timing of

562 carbonate formation. At Site C0011 the 10 temperatures determined from clumped isotopes

563 generally parallel the geothermal gradient. The geotherm is based on direct temperature

564 measurements above $200 \mathrm{mbsf}$, yielding a gradient of $91^{\circ} \mathrm{C} / \mathrm{km}$, and is extrapolated to

565 greater depth using measurements of thermal conductivity from core samples (Marcaillou et

566 al, 2012); the temperature uncertainty increases with depth. Seven of the clumped

567 measurements fall within $5^{\circ} \mathrm{C}$ of the extrapolated gradient, within clumped-isotope

568 temperature uncertainties. There is a similar trend at Site C0012, even though the gradient

569 is significantly higher $\left(135^{\circ} \mathrm{C} / \mathrm{km}\right)$. One exception is a carbonate concretion (C0012A-47R-2,

$57030-35 \mathrm{~cm}$ ) with $\sim 45 \%$ dolomite from a depth of $481 \mathrm{mbsf}$ with only a slightly depleted $\delta^{18} \mathrm{O}$

571 value. The sample appears to have retained some of its original chemical and mineralogical

572 characteristics from early precipitation at a depth closer to $\sim 40 \mathrm{mbsf}$. The other eight 
573 sediment-hosted carbonates define a downward trend in temperatures that is also parallel to

574 the temperature gradient (Marcaillou et al., 2012). Evaluation of mixing effects on clumped

575 isotope temperatures is not directly possible in this case, but given the close match for most

576 samples between calculated and measured water $\delta^{18} \mathrm{O}$ values, there is unlikely to be a

577 significant mixing offset. Any mixing offset that occurs will likely cause a slight decrease in

578 measured clumped isotope temperatures versus real precipitation temperatures (Defliese

579 and Lohmann, 2015), and would result in a closer match to the geothermal gradient. The

580 geothermal gradients at the two sites are markedly different, yet the close correspondence

581 between carbonate clumped isotope temperatures and the modern geotherms at each site is

582 compelling evidence that ${ }^{18} \mathrm{O}$-depleted carbonates of varying mineralogies have crystallized

583 recently under current temperatures.

584 In addition to oxygen and carbonate clumped isotopes, the barium and manganese

585 data support formation of many of the deeper Shikoku Basin carbonates below the SMTZ

586 and possibly recently. Data from the Cascadia margin Site U1329 provide an interesting

587 contrast (Joseph et al., 2013b). There carbonates inferred to have formed above the SMTZ

588 and now found below that zone show little enrichment in the $\mathrm{Ba} / \mathrm{Ca}$ ratios with depth, even

589 though barium in the pore fluids below the SMTZ reaches concentrations > $100 \mu \mathrm{M}$ (Fig. 7).

590 Above the SMTZ, where these carbonates likely formed, barium was sequestered into

591 barite. In marked contrast, carbonate samples from the deeper portion of the Shikoku Basin

592 do show considerable enrichment of barium. At Site C0011 Ba/Ca values in carbonates are

593 as high $5.4 \mathrm{mmol} / \mathrm{mol}$, consistent with precipitation at considerable depths where $\mathrm{Ba}$ in the

594 pore fluids reaches $150 \mu \mathrm{M}$. Carbonates from Site C0012 are also enriched in $\mathrm{Ba} / \mathrm{Ca}$ (up to

$5952 \mathrm{mmol} / \mathrm{mol}$ ) consistent with precipitation significantly below the SMTZ where dissolved $\mathrm{Ba}$

596 reaches $50 \mu \mathrm{M}$ (Fig. 7). Parallel trends in manganese concentrations in carbonate and IW at

597 Site C0012 also support recent carbonate formation at depth (Fig. 7). Mn/Ca ratios in

598 carbonates decrease steadily from $\sim 3$ to $\sim 1$ ((wt\% x10)/wt\%) from 332 to $475 \mathrm{mbsf}$. A

599 parallel decrease in manganese IW concentrations from $105 \mu \mathrm{m}$ to $10 \mu \mathrm{m}$ occurs in the

600 same depth interval (Fig. 7). Four of the carbonate samples within this trend have carbonate

601 clumped isotope data indicating recent carbonate crystallization, and we suggest the

602 manganese concentration in these carbonates is also controlled by the attendant IW

603 composition.

604

605 5.2. Carbonate formation process in the Shikoku Basin input sites

606

607

The mechanism of formation of diagenetic carbonates must explain the evidence

608 from stable isotopes, temperatures derived from carbonate clumped isotope measurements, 
609 and barium and manganese data for recent crystallization. In contrast, the strontium isotope 610 data, and to some extent carbon isotopes, suggest that some carbonates retain a relic 611 chemical signature from earlier formation. The carbonates with a "seawater" oxygen isotope

612 signature at $\mathrm{C} 0011$ are dominated by carbonates with significant R-S content that suggests

$613 \mathrm{R}-\mathrm{S}$ is a favored early carbonate phase. The presence of calcite in the shallow group

614 indicates multiple carbonates can form early in the burial history. The clumped temperatures 615 derived from ${ }^{18} \mathrm{O}$-depleted carbonates indicate that recent carbonate crystallization is 616 dominant. We argue that the diverse mixture of carbonates in this deeper group of cements 617 represents a continuum of carbonate cementation during burial in the Shikoku Basin, 618 partially preserving relic early cements while forming dominant later cements. Greater 619 prevalence of ${ }^{18} \mathrm{O}$ depletions of carbonates at $\mathrm{C} 0012$ indicates the relic shallow cement 620 signal is less well preserved, suggesting recrystallization of early cements during burial is 621 more important here. The following discussion will attempt to reconcile the multiple proxies 622 for conditions of carbonate formation.

623

$624 \quad 5.2 .1$ Role of carbon cycling

625 In marine sediments the lightest carbon available through carbon cycling is near the 626 sulfate-methane transition zone (SMTZ; Whiticar, 1999). At Site C0011, the sulfate profile 627 clearly demarcates the depth of sulfate depletion at $\sim 80 \mathrm{mbsf}$. There are limited data 628 available for $\delta^{13} \mathrm{C}$ values of dissolved inorganic carbon (DIC), but clearly the deeper 629 carbonates have a carbon isotopic composition that is depleted in ${ }^{13} \mathrm{C}$ relative to the 630 concomitant seawater, suggesting some carbonate found deep in the basin precipitated at 631 shallow depths where presumably there is a more ${ }^{13} \mathrm{C}$-depleted DIC pool.

632 At Site C0012 a similar relationship exists between carbonate carbon and DIC. Near 633 parallelism of the depth trends of $\delta^{13} \mathrm{C}$ suggest a possible relationship between the two, but 634 the carbonate carbon is lighter than would be expected for equilibrium with the $\delta^{13} \mathrm{C}$-DIC 635 (Fig. 6). It is notable that the $\delta^{13} \mathrm{C}$ minimum in sample C0012A-46R-CC, 36-40 is at a similar 636 depth to a minimum in $\delta^{13} \mathrm{C}$-DIC. This deep depletion in ${ }^{13} \mathrm{C}$ corresponds to a zone of deep 637 methane oxidation supported by sulfate diffusion from the underlying basement (Torres et 638 al., 2015). Taken together the carbon isotope characteristics of the carbonate minerals and 639 DIC suggest the deeper, recrystallized carbonate retained an inherited signal of light carbon 640 from early, shallow initial formation, but is also influenced by more recent processes.

641 Carbonate formation driven solely by carbon cycling in accretionary margins has

642 been well documented by analyses of samples recovered from the seafloor as well as 643 shallow and deep sediments (e.g., Ritger et al., 1987; Bohrmann et al., 1998; Wallman et al., 644 2008; Wehrmann et al., 2013). These carbonate phases record conditions at and below the 
645 SMTZ, where organic carbon cycling reactions are more prevalent (Whiticar, 1999), and can

646 result in a broad range of strongly depleted to enriched carbon isotopes (e.g., Sample and

647 Kopf, 1995).

648 The situation in the Shikoku Basin is, however, more complex. Here, in addition to 649 carbon cycling processes, alteration of volcanic matter and calcium diffusion from basement 650 drive the system toward additional carbonate precipitation. This could explain the lack of 651 correlation between $\delta^{18} \mathrm{O}$ and $\delta^{13} \mathrm{C}$ values. Whereas oxygen and carbon are initially

652 controlled by low-temperature alteration of sedimentary volcanic matter, there are additional 653 changes in the carbon isotopic composition due to carbon cycling driven by sulfate diffusion 654 from the basement aquifer (Torres et al., 2015).

655 We argue that ash alteration in the Shikoku basin in the zone where methanogenesis 656 produces $\mathrm{CO}_{2}$ results in a release of cations $(\mathrm{Ca}, \mathrm{Mn}, \mathrm{Fe})$ and bicarbonate that drive 657 carbonate cementation at depth as described by Wallmann et al, (2008) and summarized as: 658 cation-rich silicates (e.g., volcanic matter) $+\mathrm{CO}_{2}+\mathrm{K}^{+} \rightarrow$

660

This reaction and an additional $\mathrm{Ca}^{2+}$ source from diffusion from basement promotes saturation with respect to carbonate in pore waters. Given the changes in the $\mathrm{pH}$ of IW, carbonate diagenesis at depth may be occurring by dissolution and reprecipitation. The process could account for the lower carbonate abundance at greater depths in both sites

667 (Fig. 1), as the amount of carbonate dissolved in the zone of methanogenesis is not 668 balanced by cement formed during in situ silicate weathering.

669

\subsubsection{Strontium isotope constraints on carbonate recrystallization}

In contrast to the carbon and oxygen isotope and temperature data, strontium isotopic compositions of the cements cannot be explained as crystallization in equilibrium with current interstitial waters. The cements are isotopically more radiogenic than coexisting IW, but lower than seawater ${ }^{87} \mathrm{Sr} /{ }^{86} \mathrm{Sr}$ values contemporaneous with the depositional ages of sediment (Fig. 7). This contrasts with the results from Cascadia Site U1329, where strontium isotopic compositions of cements are consistent with precipitation in contemporaneous seawater, except for the two deepest samples, which reflect precipitation driven solely by

678 lateral flow of exotic fluids within a deep conglomerate (Joseph et al., 2013b). In the Shikoku

679 Basin, the interstitial water ${ }^{87} \mathrm{Sr} /{ }^{86} \mathrm{Sr}$ ratios are controlled by mixing of three components: 
681 with basaltic basement (Joseph et al., 2013a; Torres et al., 2015). The ${ }^{87} \mathrm{Sr} /{ }^{86} \mathrm{Sr}$ ratio for ash 682 ( 0.706; Joseph et al., 2013a) dominates the IW from 434 to $850 \mathrm{mbsf}$ at Site C0011, and 683180 to $417 \mathrm{mbsf}$ at Site C0012. This trend in isotopic values indicates alteration of volcanic 684 matter is particularly important in the interval where the carbonates analyzed in our study are 685 concentrated. Above and below the interval of ash alteration, there is evidence for diffusive 686 strontium exchange with seawater $\left({ }^{87} \mathrm{Sr} /{ }^{86} \mathrm{Sr}=0.7902\right)$ and basement $\left({ }^{87} \mathrm{Sr} /{ }^{86} \mathrm{Sr} \sim 0.703\right.$ to 687 0.705; e.g., Staudigel et al., 1981), respectively (Joseph et al., 2013a).

688 The carbonate strontium isotope values in our results can be explained as a mixture 689 between relic strontium from initial crystallization and IW modified by alteration of volcanic 690 matter. In a partially closed system the degree to which carbonates acquire new isotopic 691 values will depend on a mass balance between strontium in the IW and the original 692 carbonates. Over the depth range for which we have strontium data, pore water 693 concentrations vary from 12.6 to $22.7 \mathrm{ppm}$ (mean = $19.1 \mathrm{ppm}$ ). Strontium concentration data 694 are not available for the carbonates, but concentrations in carbonates in the Cascadia 695 accretionary prism at similar depths vary from 10.4 to 828 ppm (mean = 283 ppm; Sample 696 and Kopf, 1995; Sample and Reid, 1998). In Nankai the water-rock ratios in pore space 697 during recrystallization is not well constrained because the percent of space between grains 698 filled by carbonate is not known. Simple mass balance models show that mixing of inherited 699 strontium with contemporaneous seawater-like ${ }^{87} \mathrm{Sr} /{ }^{86} \mathrm{Sr}$ values during sediment deposition $700 \quad(0.7088)$ and IW ${ }^{87} \mathrm{Sr} /{ }^{86} \mathrm{Sr}$ modified by ash (0.7063-0.7070) can achieve the observed 701 strontium isotopes in the carbonates, which mostly range between 0.7080 and 0.7086 (see 702 Appendix). The strontium isotopic values measured in this study can be obtained for IW 703 strontium concentrations of 20 ppm and initial carbonate strontium concentrations of 50-100 $704 \mathrm{ppm}$. If higher strontium concentrations in the initial carbonate are assumed, relatively high 705 water-rock ratios are required.

706 The mixing calculations support a carbonate-formation mechanism of local 707 dissolution and re-precipitation in a closed system with respect to strontium, and provide 708 support for the inference that there is little fluid flow in these input sites (Torres et al., 2015). 709 Recrystallization of carbonates during burial in low-permeability sediment with minimal fluid 710 flow can thus lead to re-setting of $\delta^{18} \mathrm{O}$ and clumped isotope temperatures, but incomplete 711 resetting of strontium or carbon isotopes. The former are controlled by temperature and the 712 oxygen component of IW, while the latter depends on relatively low-abundance solutes 713 (strontium, carbon) in IW. Resetting of clumped isotope temperatures by solid-state diffusion 714 is not a plausible explanation given the low-temperature conditions well below the threshold 715 required for diffusion to become important (Passey and Henkes, 2012; Henkes et al., 2014).

716 The amount of fluid-carbonate isotopic exchange is negligible given the small water-rock 717 ratios. We note that the deepest two samples in Site C0012 have ${ }^{87} \mathrm{Sr} /{ }^{86} \mathrm{Sr}$ values shifted 
718 furthest from seawater toward strontium isotopic compositions similar to oceanic basement.

719 These carbonates clearly have a smaller proportion of inherited strontium than other

720 samples, and may represent a greater degree of neocrystallization.

$722 \quad$ 5.2.3 Significance of clumped-water isotope values

723 Clumped isotope analysis allows determination of the isotopic composition of pore

724 fluids at the time of carbonate formation (Eiler, 2011). In the Nankai input sites, the clumped-

725 water $\delta^{18} \mathrm{O}$ values are in some cases higher than measured modern fluids. Differences range

726 from negligible to $\sim 5 \%$ higher for clumped waters. Larger differences are found in two

727 samples with high abundance of dolomite or rhodochrosite-siderite. After correction using

728 appropriate fractionation factors (Carothers et al., 1988; Vasconcelos et al., 2005), these two

729 samples have similar differences in the offset between IW and clumped-water $\delta^{18} \mathrm{O}$ values

730 as calcite samples.. During low-temperature burial diagenesis at the input sites there are

731 multiple processes that can enrich or deplete the fluids in the heavy isotope,${ }^{18} \mathrm{O}$.

732 Precipitation of carbonate in isolated microchemical environments or movement of fluids

733 vertically in the section may play a role in developing isotopic variation. Microchemical

734 environments with fluid isotopic anomalies may not have been captured during shipboard

735 sampling of interstitial waters that took place over core intervals of $19-48 \mathrm{~cm}$ (Expedition 322

736 Scientists, 2010ab).

737 The isotopic composition of carbonates and calculated clumped fluid isotopic values

738 of carbonates is influenced by temperature and low-temperature diagenesis (Fig. 8; Eiler,

739 2011). For example, burial diagenesis of carbonates that remain in contact with open marine

740 waters would follow a trend of increasing temperatures (decreasing $\Delta_{47}$ ) and clumped fluid

741 isotopic values that remain near $0 \%$. In closed systems we might expect the fluid isotopic

742 compositions to evolve toward higher $\delta^{18} \mathrm{O}$ values due to rock-water interactions. Pore

743 waters in the Nankai input sites, however, can evolve to lower or higher $\delta^{18} \mathrm{O}$ values with

744 increasing burial due to competing processes of fluid-sediment interaction. Low-temperature

745 alteration of volcanic matter to clay depletes ${ }^{18} \mathrm{O}$ in fluids (Gieskes and Lawrence, 1981).

746 This process can continue to temperatures up to $150^{\circ} \mathrm{C}$ (Alt et al., 1986) and is likely

747 responsible for the observed decrease of IW $\delta^{18} \mathrm{O}$ values with depth. In contrast, diagenetic

748 alteration of smectite to illite releases ${ }^{18} \mathrm{O}$-enriched clay-bound water (Perry et al., 1976; Yeh

749 and Savin, 1977; Primmer and Shaw, 1990) to mix with existing pore water. In most geologic

750 settings this process becomes important at $60^{\circ} \mathrm{C}$ and can continue up to $\sim 150^{\circ} \mathrm{C}$ (Pytte and

751 Reynolds, 1988; Saffer et al., 2008).

752 The oxygen isotopic compositions calculated for clumped waters may reflect a

753 mixture of waters from original seawater trapped during initial burial, clay diagenesis, and 
754 alteration of volcanic matter. Of the 19 sediment cements we analyzed, five have clumped

755 water isotopic values close to the interstitial water isotope values measured from core

756 samples (Figs. 5 and 6). The five are consistent with fluids dominated isotopically by

757 alteration of reactive silicates to clays. The remaining 14 samples are more enriched in ${ }^{18} \mathrm{O}$

758 than coexisting IW. Nearly all of these have clumped-water $\delta^{18} \mathrm{O}$ values $\leq 1 \%$. The exception

759 is a dolomite cement. For the majority of samples a mixture of fluids between a marine

760 endmember and lighter waters derived from the alteration of reactive silicates could explain

761 the isotopic variations (Fig. 8). Alternatively, clay diagenesis resulting inenrichment of fluids

762 in ${ }^{18} \mathrm{O}$ is most likely to occur near the bottom of each input site, where temperatures exceed

$76360^{\circ} \mathrm{C}$, the threshold for the smectite-illite transition. For shallower samples with high

764 clumped-water $\delta^{18} \mathrm{O}$ values upward diffusion or advection of heavy waters is required.

765 Possible chemical diffusion is indicated by chemical profiles such as chlorinity and sulfate

766 (Torres et al., 2015). There are also trends toward slightly higher values near the base of the

767 IW $\delta^{18} \mathrm{O}$ profiles suggesting possible diffusion from deeper, heavier IW from an ${ }^{18} \mathrm{O}$-enriched 768 source.

769 An alternative explanation for enrichment of ${ }^{18} \mathrm{O}$ in clumped water isotopes is

770 disequilibrium precipitation. Disequilibrium commonly results in low $\Delta_{47}$ and high

771 temperatures relative to the observed conditions a variety of settings (Tripati et al., 2005;

772 Affek et al., 2008; Thiagarajan et al., 2011; Loyd et al., 2016) or predicted from theoretical

773 calculations (Guo et al., 2009; Hill et al., 2014). Disequilibrium does not seem a likely

774 explanation to explain results from Nankai input sites. Shallow carbonates formed at cool

775 temperatures do not exhibit the expected anomalously low $\Delta_{47}$ values as might be expected.

776 There are no systematic anomalies in clumped-water isotope values related to depth or

777 temperature of formation. Carbonates in deeper samples formed at higher temperatures,

778 conditions under which disequilibrium effects have not been observed in other settings.

779 Based on analysis of the mineralogy, and the downhole temperature trends in

780 clumped temperatures and fluid isotopes, we conclude that cementation occurred generally

781 in equilibrium with current downhole temperatures, in microchemical environments that are

782 not well characterized with respect to oxygen isotope compositions by bulk measurement of

783 interstitial water chemistry. Further work in volcaniclastic deep marine settings at other

784 convergent margins and at deeper portions of the Nankai accretionary prism, utilizing

785 smaller interstitial water samples in close association with cemented horizons, might clarify

786 the relationship between clumped-water and in situ IW isotopes.

$788 \quad 5.3$ Carbonate formation history and relevance to properties of input sediments 
The results of this study indicate carbonate formation is an important active process in the Shikoku Basin throughout burial and includes dissolution and re-precipitation at depth.

791 Temperatures from clumped-carbonate isotope geochemistry show the prevalence of in situ 792 carbonate dissolution and recrystallization or neocrystallization. The clumped data are 793 supported by widespread ${ }^{18} \mathrm{O}$-depleted cements and by textures showing partial dissolution 794 of R-S (Fig. 3). As diagenesis of organic matter proceeds below the SMTZ, increasing 795 carbon dioxide levels from methanogenesis lower the $\mathrm{pH}$ and induce at least partial dissolution of the carbonate (Fig. 9; Wallman et al., 2008). Local alteration of volcanic matter driven by changes in $\mathrm{pH}$ by methanogenesis can lead to local environments with increased alkalinity and carbon re-precipitation (reaction 1). Replacement textures of ash by calcite and R-S are observed in support of this mechanism (Fig. 3). The space occupied by individual clots of carbonate, with quartz inclusions, is consistent with nucleation and growth of new carbonate in space that is larger than original pore space, by reaction (1) involving replacement of volcanic matter. The result is formation of cement that is combined clay, carbonate, and to a lesser extent silica during burial diagenesis.

Carbonate-clumped isotope data support the recent timing of carbonate formation. Inferences about timing process depend in part on the $\Delta_{47}$-temperature calibration chosen. For the carbonate-clumped temperature values we used the calibration of Tripati et al. (2015). Using other calibrations (e.g., Defliese et al., 2015; Kluge et al., 2015) yielded higher temperatures for most samples, in many cases well above the measured geothermal gradients. The results from the Nankai input sites provide valuable information for evaluation of different clumped isotope-temperature calibrations. For our results we compared two calibrations (Tripati et al., 2015; Tang et al., 2014; see Appendix). Both are based on

812 measurements made on similar instrumentation, and both include measurements made at 813 the UCLA lab also used for our study. The steep-sloped calibration curve has a narrower 814 range of temperature values over the range of measured $\Delta_{47}$ values in this study (Tripati et 815 al., 2015). It yields somewhat higher temperatures at high $\Delta_{47}$ values, but for most samples 816 the temperatures from this calibration are lower compared with the shallow-sloped 817 calibration of Tang et al. (2014). Their calibration yields a larger range of temperature and 818 higher temperatures for low $\Delta_{47}$ values. The steep-sloped calibration yields results most 819 consistent with geothermal gradients at both input sites (Figs. 5 and 6). The calculated 820 clumped water $\delta^{18} \mathrm{O}$ values for this calibration are closer to measured, modern interstitial 821 water $\delta^{18} \mathrm{O}$ values as well. If the calibration of Tang et al. (2014) is used, more temperatures 822 lie well above the geothermal gradients, and the clumped fluid $\delta^{18} \mathrm{O}$ values are further from 823 measured IW values. There is no clear evidence for widespread geothermal activity in the 824 past that would account for the temperatures elevated about the current gradient. We 
825 conclude that for carbonate diagenesis in these siliciclastic-dominated, deep-sea sediments,

826 the calibration of Tripati et al. (2015) is more reliable. Our results provide a new benchmark

827 for clumped isotope temperature calibrations that can be tested with further studies from

828 drilling in similar settings.

829 A powerful result form our study is the demonstration that clumped isotopes from

830 carefully chosen samples can be used to determine successfully the geothermal gradient to

831 oceanic basement where other more direct measurements may not be available. In general

832 direct borehole temperature measurements subduction systems are limited to depths of a

833 few hundred meters (e.g., Harris et al., 2011). The slightly elevated temperatures from the

834 bottom of Site C0012 provide evidence that in the past, periodically warmer fluids escaped

835 from the crest of the basement high at Kashinosaki Knoll into the overlying sedimentary

836 column. The ability to constrain temperatures with clumped isotope data is a significant

837 result, as temperature histories of buried, clay-rich sediments provide important information

838 about the potential for clay mineral diagenesis, the development of related excess pore

839 pressures, and the variations in seismogenic response of these sediments during faulting

840 (Saffer and Wallace, 2015).

841 Carbonate cementation can also affect the physical properties of sediments and

842 preserve information about the condition under which lithification occurs. In ancient

843 convergent margins the chemistry of carbonate veins is an important proxy for changes in

844 fluid sources, evolution of pore fluid pressure, and changes in strength parameters of

845 sediments (Dieldorfer et al., 2015). In active margins interseismic healing in faults by

846 cementation results in an increase of fault strength due to an increase in the grain contact

847 area and cohesion (Tenthorey and Cox, 2006; Ikari et al., 2016). Carbonate cementation can

848 facilitate velocity-weakening behavior in a fault zone and interseismic recovery of strength,

849 both characteristics of faults experiencing repeated seismic rupture (Chen et al., 2012; Ikari

850 et al., 2016). As sediment enters the accretionary prism, the presence of carbonate cements

851 like those documented here may enhance the probability for this strengthening effect where

852 major faults localize in cemented horizons. Carbonate cementation driven by sub-seafloor

853 alteration of volcaniclastic sediment locally composes $10-20 \%$ of the solids and may

854 continue during subduction and accretion. Early results from drilling to depths of $3000 \mathrm{mbsf}$

855 into the Nankai prism show that carbonates veins and cements are commonly associated

856 with fault zones (Expedition 348 Scientists, 2015b).

857

\section{CONCLUSIONS}

859 Carbonate mineralogy, composition, strontium and stable isotope data, including

860 carbonate clumped isotope thermometry, provide constraints on the mechanism and timing

861 of carbonate formation in incoming sediments to the Nankai subduction zone. While 
862 carbonate cements begin to form very early in the burial history, there is evidence from

863 barium and carbonate-clumped isotope temperatures that carbonate continues to precipitate

864 throughout burial. Other chemical data support retention of some of the early history of

865 carbonate cementation in the recrystallized carbonate. The process of lithification due to

866 carbonate cementation likely involves dissolution and re-precipitation under current

867 temperature conditions. As is known for continental margins worldwide, carbonate formation

868 can be relatively common above the SMTZ, where carbonate forms because sulfate

869 reduction and anaerobic oxidation of methane result in an increase in alkalinity. Here we

870 show that in addition to these early methane-derived authigenic carbonates, ash alteration at

871 greater depths consumes protons released during methanogenesis, and thus constitutes an

872 additional source of alkalinity (Wallmann et al., 2008). Added to this, there a continuous

873 supply of calcium by alteration of volcanogenic materials (ash and underlying basaltic

874 basement) that maintains supersaturation with respect to calcite. The clumped isotope

875 temperatures derived from samples ranging from 69 to $762 \mathrm{mbsf}$ are in agreement with

876 current temperature gradient estimates, documenting that the main fraction of the carbonate

877 at depth formed in situ. The various temperature data indicate that the carbonate clumped

878 temperature calibration of Tripati et al. (2015) is most suitable for the Shikoku, and we

879 believe will also apply to other siliciclastic, carbonated-cemented sedimentary basins. Our

880 results highlight the importance of using multi-proxy approaches to elucidate the history of

881 carbonate cementation, establish carbonate cementation at depth, and its potential impact

882 on the physical properties of the sediment. We demonstrate that carbonate clumped isotope

883 thermometry is a useful tool in constraining geothermal gradients in subduction systems.

884

\section{Acknowledgments}

886 We thank P. Agrinier, Ben Elliott, C. Joseph, B. Moan, Antra Priyardishi, and J. Wittke

887 for assistance with the analytical tasks described here. This research used samples and

888 data provided by the Integrated Ocean Drilling Program (IODP), which is sponsored by the

889 US National Science Foundation and participating countries under management of IODP-

890 MI. We gratefully acknowledge the efforts of the D/V Chikyu shipboard and drilling personnel

891 and of the Scientific Parties of IODP Expeditions 322 and 333. Funding for this research was

892 provided by the National Science Foundation (OCE-1029972, OCE-1029981, EAR-

893 1325054, and EAR-0949191), ACS-PRF award 51182-DNI2, and a LabEx International

894 Research Chair funded by the "Laboratoire d'Excellence" LabexMER (ANR-10-LABX-19) co-

895 funded by a grant from the French government under the program "Investissements

896 d'Avenir". WFD was supported by a GDL Foundation Award in Structure and Diagenesis.

897 Clumped isotope analyses and AET were supported by the U.S. Department of Energy,

898 Office of Science, Office of Basic Energy Sciences, Chemical Sciences, Geosciences, and 
899 Biosciences Division under Award Number DE-FG02-13ER16402. In addition, we

900 acknowledge support from the Helen R. Whitely Center at the University of Washington

901 Friday Harbor Laboratory through the Whitely Scholars Program to JS, and the Hanse-

902 Wissenschaftskolleg, Institute for Advanced Study in Delmenhorst, Germany through a

903 fellowship to MT during the spring of 2013.

904

905 References Cited

906 Affek, H. P., Bar-Matthews, M., Ayalon, A., Matthews, A. and Eiler, J. M., 2008.

907 Glacial/interglacial temperature variations in Soreq cave speleothems as recorded by

908 'clumped isotope' thermometry, Geochim. Cosmochim. Acta 72, 5351-5360.

909 Alt, J. C., K. Muehlenbachs, and J. Honnorez, 1986. An oxygen isotopic profile through the

910 upper kilometer of the oceanic crust, DSDP Hole 504B: Earth and Planetary Scwnce

911 Letters, 80, 217-229.

912 Bayon, G., C. Pierre, J. Etoubleau, M. Voisset, E. Cauquil, T. Marsset, N. Sultan, E.

913 LeDrezen, and Y. Fouquet, 2007. Sr/Ca and Mg/Ca ratios in Niger Delta sediments:

914 Implications for authigenic carbonate genesis in cold seep environments. Marine

915 Geology 241, 93-109.

916 Bohrmann, G., Greinert, J., Suess, Erwin., and Torres, M., 1998. Authigenic carbonates from

917 the Cascadia subduction zone and their relation to gas hydrate stability: Geology 26,

918 647-650.

919 Campbell, K. A., J. D. Farmer and D. Des Marais, 2002. Ancient hydrocarbon seeps from

920 the Mesozoic convergent margin of California: carbonate geochemistry, fluids and

921 palaeoenvironments: Geofluids 2, 63-94.

922 Carothers, William W., Lanford H. Adami and Robert J. Rosenbauer, 1988. Experimental

923 oxygen isotope fractionation between siderite-water: Geochimica et Cosmochimica Acta

$924 \quad 52,2445-2550$.

925 Defliese, W. F., and K. C. Lohmann, 2015. Non-linear mixing effects on mass-47 $\mathrm{CO}_{2}$

926 clumped isotope thermometry: patterns and implications. Rapid Communications in

927 Mass Spectrometry 29, 901-909.

928 Defliese, W. F., M. T. Hren, and K. C. Lohmann, 2015. Compositional and temperature

929 effects of phosphoric acid fractionation on $\Delta_{47}$ analysis and implications for discrepant

930 calibrations: Chemical Geology 396, 51-60.

931 Defliese, W. F., and A. E. Tripati, 2016. Analytical effects on clumped isotope thermometry:

932 Comparison of a common sample set run using multiple instruments and methods, 5th

933 International Clumped Isotope Workshop, St. Petersburg, Florida 
934 Dennis, K. J., Affek, H. P., Passey, B. H., Schrag, D. P., and Eiler, J. M., 2011. Defining an absolute reference frame for 'clumped' isotope studies of $\mathrm{CO}_{2}$. Geochimica et Cosmochimica Acta, 75(22), 7117-7131.

Dielforder, A., Vollstaedt, H., Vennemann, T., and Berger, A., Herwegh, M., 2015. Linking megathrust earthquakes to brittle deformation in a fossil accretionary complex, Nature Communications 6, 7504. DOI: 10.1038/ncomms8504

Eagle, R. A., Schauble, E. A., Tripati, A. K., Tütken, T., Hulbert, R. C., and Eiler, J. M., 2010. Body temperatures of modern and extinct vertebrates from ${ }^{13} \mathrm{C}-{ }^{18} \mathrm{O}$ bond abundances in bioapatite. Proc. Natl. Acad. Sci. 107, 10377-10382.

Eagle, R. A., Tütken, T., Martin, T. S., Tripati, A. K., Fricke, H. C., Connely, M., Cifelli, R. and Eiler, J. M., 2011. Dinosaur body temperatures determined from isotopic $\left({ }^{13} \mathrm{C}-{ }^{18} \mathrm{O}\right)$ ordering in fossil biominerals. Science 333, 443-445.

Eagle, R.A., Eiler, J.M., Tripati, A.K., Ries, J.B., Freitas, P.S., Hiebenthal, C., Wanamaker Jr, A.D., Taviani, M., Elliot, M., Nakamura, K., Ramirez, P., Marenssi, S., and Roy, K., 2013. The influence of temperature and seawater carbonate saturation state on ${ }^{13} \mathrm{C}-{ }^{18} \mathrm{O}$ bond ordering in bivalve mollusks. Biogeosciences 10, 157-194.

Eiler, J., and Schauble, E., 2004. ${ }^{18} \mathrm{O}^{13} \mathrm{C}^{16} \mathrm{O}$ in Earth's atmosphere. Geochim. Cosmochem. Acta 68, 4767-4777.

Eiler, J. M., 2007. 'Clumped-isotope' geochemistry-The study of naturally-occurring multiplysubstituted isotopologues. Earth Planet. Sci. Lett. 262, 309-327.

Expedition 322 Scientists, 2010a. Site C0011. In Saito, S., Underwood, M.B., Kubo, Y., and the Expedition 322 Scientists, Proc. IODP, 322: Tokyo (Integrated Ocean Drilling Program Management International, Inc.). doi:10.2204/iodp.proc.322.103.2010.

Expedition 322 Scientists, 2010b. Site C0012. In Saito, S., Underwood, M.B., Kubo, Y., and the Expedition 322 Scientists, Proc. IODP, 322: Tokyo (Integrated Ocean Drilling Program Management International, Inc.). doi:10.2204/iodp.proc.322.104.201.

Expedition 333 Scientists, 2012a. Site C0012. In Henry, P., Kanamatsu, T., Moe, K., and the Expedition 333 Scientists, Proc. IODP, 333: Tokyo (Integrated Ocean Drilling Program Management International, Inc.). doi:10.2204/iodp.proc.333.105.2012.

Expedition 333 Scientists, 2012b. Site C0011. In Henry, P., Kanamatsu, T., Moe, K., and the Expedition 333 Scientists, Proc. IODP, 333: Tokyo (Integrated Ocean Drilling Program Management International, Inc.). doi:10.2204/iodp.proc.333.104.2012.

Expedition 348 Scientists, 2015a. Methods. In Tobin, H., Hirose, T., Saffer, D., Toczko, S., Maeda, L., Kubo, Y., and the Expedition 348 Scientists, Proc. IODP, 348: College Station, TX (Integrated Ocean Drilling Program). doi:10.2204/iodp.proc.348.102.2015. 
969

Expedition 348 Scientists, 2015b. Site C0002. In Tobin, H., Hirose, T., Saffer, D., Toczko, S., Maeda, L., Kubo, Y., and the Expedition 348 Scientists, Proc. IODP, 348: College Station, TX (Integrated Ocean Drilling Program). doi:10.2204/iodp.proc.348.103.2015. Ghosh, P., Adkins, J., Affek, H., Balta, B., Guo, W., Schauble, E. A., Schrag, D., and Eiler, J. M., 2006. ${ }^{13} \mathrm{C}-{ }^{18} \mathrm{O}$ bonds in carbonate minerals: A new kind of paleothermometer. Geochim Cosmochem Acta 70, 1439-1456.

Gieskes, J. M., and Lawrence, J. R., 1981. Alteration of volcanic matter in deep sea sediments: evidence from the chemical composition of interstitial waters from deep sea drilling cores. Geochim. Cosmochim. Acta, 45, 1687-1703.

Guo, W., Mosenfelder, J. L., Goddard, W. A. and Eiler, J. M., 2009. Isotopic fractionations associated with phosphoric acid digestion of carbonate minerals: Insights from firstprinciples theoretical modeling and clumped isotope measurements, Geochim. Cosmochim. Acta 73, 7203-7225.

Harris, R. N., Schmidt-Schierhorn, F., and Spinelli, G., 2011. Heat flow along the NanTroSEIZE transect: Results from IODP Expeditions 315 and 316 offshore the Kii Peninsula, Japan, Geochemistry, Geophysics, Geosystems 12, Q0AD16, doi:10.1029/2011GC003593

Henkes, G. A., B. H. Passey, A. D. Wanamaker Jr., E. L. Grossman, W. G. Ambrose Jr., and M. L. Carroll, 2013. Carbonate clumped isotope compositions of modern marine mollusk and brachiopod shells. Geochimica et Cosmochimica Acta 106, 307-325.

Henkes, G. A., B. H. Passey, E. L. Grossman, B. J. Shenton, A. Pérez-Huerta, T. E. Yancey, 2014. Temperature limits for preservation of primary calcite clumped isotope paleotemperatures, Geochimica et Cosmochimica Acta: 139, 362-382. doi: 10.1016/j.gca.2014.04.040.

Henry, P., Kanamatsu, T., Moe, K., and the Expedition 333 Scientists, 2012. Proc. IODP, 333: Tokyo (Integrated Ocean Drilling Program Management International, Inc.). doi: 10.2204/iodp.proc.333.2012

Hess, J., M. L. Bender, and J.-G. Schilling, 1986. Evolution of the Ratio of Strontium-87 to Strontium-86 in Seawater from Cretaceous to Present: Science, 231, 979-984.

Hill, P. S., Tripati, A. K. and Schauble, E. A., 2014. Theoretical constraints on the effects of $\mathrm{pH}$, salinity, and temperature on clumped isotope signatures of dissolved inorganic carbon species and precipitating carbonate minerals, Geochim. Cosmochim. Acta 125, 610-652.

Huntington, K. W., Eiler, J. M., Affek, H. P., Guo, W., Bonifacie, M., Yeung, L. Y., Thiagarajan, N., Passey, B., Tripati, A., Daeron, M. and Came, R., 2009. Methods and limitations of 'clumped' $\mathrm{CO}^{2}$ isotope $\left(\Delta_{47}\right)$ analysis by gas-source isotope-ratio mass spectrometry. J. Mass Spectrom. 44, 1318-1329. 
Ikari, M. J., D. M. Saffer, and C. Marone, 2009. Frictional and hydrologic properties of clayrich fault gouge: Journal of Geophysical Research 114, B05409, doi:10.1029/2008JB006089.

Joseph, C., Torres, M. E. and Haley, B. A., 2013a. Data Report: ${ }^{87} \mathrm{Sr} /{ }^{86} \mathrm{Sr}$ in Pore Fluids from NantroSeize Expeditions 322 and 333. In Saito, S., Underwood, M.B., Kubo, Y., and the Expedition 322 Scientists, Proceedings Integrated Ocean Drilling Program, 322: Tokyo (Integrated Ocean Drilling Program Management International, Inc.). doi:10.2204/ iodp.proc.322.204.2013

Joseph, C., Torres, M.E., Martin, R.A., Haley, B.A., Pohlman, J.W., Riedel, M., and Rose, K., 2013b. Using the ${ }^{87} \mathrm{Sr} /{ }^{86} \mathrm{Sr}$ of modern and paleoseep carbonates from northern Cascadia to link modern fluid flow to the past. Chemical Geology 334:122-130.

Kim, S-T. and O'Neil, J. R., 1997. Equilibrium and nonequilibrium oxygen isotope effects in synthetic carbonates, Geochimica et Cosmochimica Acta, v. 61, 3461-3475.

Kluge, T., C. M. John, A.-L. Jourdan, S. Davis, and J. Crawshaw, 2015. Laboratory calibration of the calcium carbonate clumped isotope thermometer in the $25-250{ }^{\circ} \mathrm{C}$ temperature range: Geochimica et Cosmochimica Acta 157, 213-227.

Loyd, Sean J., Corsetti, Frank A., Eiler, John M., and Tripati, Aradhna K., 2012. Determining the diagenetic conditions of concretion formation: assessing temperatures a pore waters using clumped isotopes. Journal ff Sedimentary Research 82, 1006-1016.

Marcaillou, B., P. Henry, M. Kinoshita, T. Kanamatsu, E. Screaton, H. Daigle, V. HarcouëtMenou, Y. Lee, O. Matsubayashi, M. Kyaw Thu, S. Kodaira, M. Yamano, and the IODP Exepdition 333 scientific party, 2012. Seismogenic zone temperatures and heat-flow anomalies in the To-nankai margin segment based on temperature data from IODP expedition 333 and thermal model: Earth and Planetary Science Letters 349-350, 171185

Moore, J. C., and P. Vrolijk, 1992. Fluids in accretionary prisms: Reviews of Geophysics 30, 113- 135.

Moore, J. C., and Saffer, D., 2001. Updip limit of the seismogenic zone beneath the accretionary prism of southwest Japan: An effect of diagenetic to low-grade metamorphic processes and increasing effective stress. Geology, 29(2), 183-186.

Passey, B. H., and Henkes, G. A., 2012. Carbonate clumped isotope bond reordering and geospeedometry. Earth Planet. Sci. Lett. 351, 223-236.

Passey, B. H., Levin, N. E., Cerling, T. E., Brown, F. H. and Eiler, J. M., 2010. Hightemperature environments of human evolution in East Africa based on bond ordering in paleosol carbonates. PNAS 107, 11245-11249. 
1041

1042

1043

1044

1045

1046

1047

1048

1049

1050

1051

1052

1053

1054

1055

1056

1057

1058

1059

1060

1061

1062

1063

1064

1065

1066

1067

1068

1069

1070

1071

1072

1073

1074

1075

1076

Perry, E.A., Gieskes, J.M. and Lawrence, J.R. (1976) Mg, Ca and 18O/16O exchange in the sediment-pore water system, Hole 149, DSDP. Geochemica et Cosmochimica Acta 40, 413-423.

Pingitore, NE, 1978. Behavior of $\mathrm{Zn}^{2+}$ And $\mathrm{Mn}^{2+}$ During Carbonate Diagenesis - Theory and Applications. Journal Of Sedimentary Petrology 48, 799-814.

Primmer, T.J. and Shaw, H. (1990) Variations in the $\delta \mathrm{D}$ and $\delta^{18} \mathrm{O}$ compositions of illitesmectites in a partly overpressured Tertiary sequence from an offshore well, Texas Gulf Coast, USA. Marine and Petroleum Geology 8, 225-231.

Ritger, S., Carson, B., and Suess, E., 1987, Methane-derived authigenic carbonates formed by subduction-induced pore-water expulsion along the Oregon/Washington margin: Geological Society of America Bulletin, v. 98, p. 147-156.

Rosenheim, B. E., Tang, J., and Fernandez, A., 2013. Measurement of multiply substituted isotopologues ('clumped isotopes') of $\mathrm{CO}_{2}$ using a $5 \mathrm{kV}$ compact isotope ratio mass spectrometer: Performance, reference frame, and carbonate paleothermometry. Rapid Commun. Mass Spectrom. 27, 1847-1857.

Saffer, Demian M., Michael B. Underwood, and Alexander W. Mckiernan, 2008. Evaluation of factors controlling smectite transformation and fluid production in subduction zones: Application to the Nankai Trough, Island Arc 17, 208-230.

Saffer, Demian M., and Harold J. Tobin, 2011. Hydrogeology and Mechanics of Subduction Zone Forearcs: Fluid Flow and Pore Pressure, Annu. Rev. Earth Planet. Sci. 39:15786.

Saffer, D. M., and L. M. Wallace, 2015. The frictional, hydrologic, metamorphic and thermal habitat of shallow slow earthquakes, Nature Geoscience 8, 594-600.

Saito, S., Underwood, M.B., Kubo, Y., and the Expedition 322 Scientists, Proc. IODP, 322 : Tokyo (Integrated Ocean Drilling Program Management International, Inc.). doi:10.2204/iodp.proc.322.103.2010

Sakai, H., Gamo, T., Ogawa, Y., and Boulegue, J.,1992. Stable isotopic ratios and origins of the carbonates associated with cold seepage at the eastern Nankai Trough. Earth and Planetary Science Letters, 109(3), 391-404.

Sample, J. C. 1990. The Effect of Carbonate Cementation of Underthrust Sediments on Deformation Styles During Underplating, Journal of Geophysical Research, vol. 95, p. 9111-9121.

Sample, J.C., and Kopf, A., 1995, Geochemistry of syntectonic carbonate cements and veins from the Oregon margin (ODP Leg 146): Implications for the hydrogeologic evolution of the accretionary wedge. In Carson, B., Westbrook, G., Musgrave, R. et al., Proc. ODP, Sci. Results, 146: College Station, TX (Ocean Drilling Program), p. 137-148. 
Sample, J.C., and Reid, M.R., 1998, Contrasting Hydrogeologic Regimes Along Strike-Slip and Thrust Faults in the Oregon Convergent Margin: Evidence From the Chemistry of Syntectonic Carbonate Cements and Veins: Geological Society of America Bulletin, v. 110 , p. 48-59.

Sample, J. C., 2010. Stable isotope constraints on vein formation and fluid evolution along a recent thrust fault in the Cascadia accretionary wedge. Earth and Planetary Science Letters 293: 300-312.

Schrag, D. P., Higgins, J. A., Macdonald, F. A., and Johnston, D. T., 2013. Authigenic carbonate and the history of the global carbon cycle. Science, 339(6119), 540-543.

Solomon; E. A., A. J. Spivack, M. Kastner, M. E. Torres, and G. Robertson, 2014. Gas hydrate distribution and carbon sequestration through coupled microbial methanogenesis and silicate weathering in the Krishna-Godavari basin, offshore India: Marine and Petroleum Geology 58, 233-253.

Staudigel, H., S. R. Hart, and S. H. Richardson, 1981. Alteration of the Oceanic Crust: Processes and Timing: Earth and Planetary Science Letters, 52: 311-327.

Tang, J., M. Dietzel, A. Fernandez, A. K. Tripati, and B. E. Rosenheim, 2014. Evaluation of kinetic effects on clumped isotope fractionation $\left(\Delta_{47}\right)$ during inorganic calcite precipitation: Geochimica et Cosmochimica Acta 134, 120-136.

Thiagarajan, N., Adkins, J. and Eiler, J., 2011. Carbonate clumped isotope thermometry of deep-sea corals and implications for vital effects. Geochim. Cosmochim. Acta 75, 44164425.

Tobin, H., Kinoshita, M., Ashi, J., Lallemant, S., Kimura, G., Screaton, E., Moe, K.T., Masago, H., Curewitz, D., and the Expedition 314/315/316 Scientists, 2009. NanTroSEIZE Stage 1 expeditions: introduction and synthesis of key results. In Kinoshita, M., Tobin, H., Ashi, J., Kimura, G., Lallemant, S., Screaton, E.J., Curewitz, D., Masago, H., Moe, K.T., and the Expedition 314/ 315/316 Scientists, Proc. IODP, 314/315/316: Washington, DC (Integrated Ocean Drilling Program Management International, Inc.). doi:10.2204/iodp.proc.314315316.101.2009.

Torres, M.E., Brumsack, H.J., Bohrmann, G., and Emeis, K.C., 1996. Barite fronts in continental margin sediments: A new look at barium remobilization in the zone of sulfate reduction and formation of heavy barites in diagenetic fronts. Chemical Geology 127, 125-139.

Torres, M. E., Mix, A. C., and Rugh, W. D., 2005. Precise delta C-13 analysis of dissolved inorganic carbon in natural waters using automated headspace sampling and continuous-flow mass spectrometry. Limnology and Oceanography-Methods: 3: 349360.

Torres, M. E., R. A. Martin, G. P. Klinkhammer, and E. A. Nesbitt, 2010. Post depositional alteration of foraminiferal shells in cold seep settings: New insights from flow-through 

time-resolved analyses of biogenic and inorganic seep carbonates. Earth and Planetary Science Letters 299, 10-22.

Torres, M. E., T. Cox, W.-L. Hong, J . Mcmanus, J.C. Sample, C. Destrigneville, H. M. Gan, H. Y. Gan, and J. W. Moreau, 2015. Crustal fluid and ash alteration impacts on the biosphere of Shikoku Basin sediments, Nankai Trough, Japan, Geobiology 13, 562-580. DOI: 10.1111/gbi.12146.

Tripati, A., Backman, J., Elderfield, H. and Ferretti, P., 2005. Eocene bipolar glaciation associated with global carbon cycle changes, Nature 436, 341-346.

Tripati, A. K., Eagle, R. A., Thiagarajan, N., Gagnon, A. C., Bauch, H., Halloran, P. R., and Eiler, J. M., 2010. ${ }^{13} \mathrm{C}-{ }^{18} \mathrm{O}$ isotope signatures and 'clumped isotope' thermometry in foraminifera and coccoliths. Geochim. Cosmochim. Acta 74, 5697-5717.

Tripati, A. K., J. C. Sample, 2012. Clumped isotope analyses of Cascadia margin carbonate cements and veins recovered by the Ocean Drilling Program constrain temperatures in the prism during subduction, Abstract T13B-2606 presented at 2012 Fall Meeting, AGU, San Francisco, Calif., 3-7 Dec.

Tripati, Aradhna K., Hill, Pamela S., Eagle, Robert A., Mosenfelder, Jed L., Tang, Jianwu, Schauble, Edwin A., Eiler, John M., Zeebe, Richard E., Uchikawa, Joji, Coplen, Tyler B., Ries, Justin B., and Henry, Drew, 2015. Beyond temperature: Clumped isotope signatures in dissolved inorganic carbon species and the influence of solution chemistry on carbonate mineral composition. Geochim. Cosmochim. Acta 166, 344-371. DOI: 10.1016/j.gca.2015.06.021

Tucker, M. E., 1992. The Precambrian Cambrian Boundary - Seawater Chemistry, Ocean Circulation and Nutrient Supply in Metazoan Evolution, Extinction and Biomineralization. Journal of the Geological Society 149, 655-668.

Vasconcelos, C., J. A. McKenzie, R. Warthmann, and S. M. Bernasconi, 2005. Calibration of the $\delta^{18} \mathrm{O}$ paleothermometer for dolomite precipitated in microbial cultures and natural environments 33, 317-320. doi: 10.1130/G20992.1.

Veizer J., 1983. Trace Elements and Isotopes in Sedimentary Carbonates, in, Reviews in Mineralogy: Carbonates, ed. R. J. Reeder, v. 11, p. 265 - 300.

Veizer, J., D. Ala, K. Azmy, P. Bruckschen, D. Buhl, F. Bruhn, G. A. F. Carden, A. Diener, S. Ebneth, Y. Godderis, T. Jasper, C. Korte, F. Pawellek, O. G. Podlaha, H. Strauss, 1999, $87 \mathrm{Sr} / 86 \mathrm{Sr}$, $\mathbf{1 3 \mathrm { C }}$, and $\delta 180$ evolution of Phanerozoic seawater, Chemical Geology 161 , 1999 59-88

Wallmann, K., G. Aloisi, M. Haeckel, P. Tishchenko, G. Pavlova, J. Greinert, S. Kutterolf, and A. Eisenhauer, 2008. Silicate weathering in anoxic marine sediments. Geochimica et Cosmochimica Acta 72, 3067-3090. 
Wehrmann, L. M., C. Ockert, A. C. Mix, N. Gussone, B. M. A. Teichert, and P. Meister, 2013. Repeated occurrences of methanogenic zones, diagenetic dolomite formation and linked silicate alteration in southern Bering Sea sediments (Bowers Ridge, IODP Exp. 323 Site U1341). Deep-Sea Research II, available online 25 September $2013 .$.

Whiticar, M. J., 1999. Carbon and hydrogen isotope systematics of bacterial formation and oxidation of methane. Chemical Geology 161, 291-314.

Yeh, H.-W. and Savin, S.M. (1977) Mechanism of burial metamorphism of argillaceaous sediments: O-isotope evidence. Geological Society of American Bulletin 88, 1321-1330.

\section{List of Tables}

1162 Table 1. Carbonate geochemical data.

Table 2. Carbonate clumped isotope data.

\section{Figure Captions}

Figure 1. Index map (A), seismic reflection profile showing locations of IODP Sites C0011 and C0012 (B), and shipboard total carbonate results (coulometric method) (modified from

1170 Expedition 322 scientists, 2010ab (diamonds) and Expedition 333 Scientists, 2012ab

1171 (circles)). Sediment cores were collected to depths of $881 \mathrm{mbsf}$ at Site C0011 and $538 \mathrm{mbsf}$ 1172 at Site C0012.

Figure 2. A. Lithologies from coring during Expeditions 322 and 333 (from Expeditions 333 Scientists, 2012b). Unit designations shown by Roman numerals next to lithologic columns. Diagonal-line patterns are slumped intervals. Depths in meters below seafloor (mbsf). Agedepth models based on nannofossils, magnetostratigraphy, and tephrochronology are shown in $\mathrm{B}$.

1180 Figure 3. Representative SEM-EDS spectra for solid solution rhodochrosite-siderite (R-S) (A) and Mn-calcite (B) from sample 322-C0011B-39R-2. Also shown are typical textures of secondary carbonate imaged by SEM backscattered electrons. C) Segregated clots of Mgcalcite (MC) and smectite (SM). D) Clot of Mg-calcite with idiomorphic solid-solution R-S and small inclusions of secondary quartz (Q). R-S also occurs in the smectite-rich matrix. E) Partial replacement $(r)$ of volcanic ash and silicates by calcite $(C)$. 
1187 Figure 4. Ternary diagrams showing normalized compositions of carbonates from electron1188 probe microanalysis in mol\% oxides. Dominant cements are Mn-calcite. Note substitution of $1189 \mathrm{MgO}$ is minor.

1190

1191 Figure 5. Depth plots for Site $\mathrm{C} 0011$ of $\delta^{18} \mathrm{O}(\mathrm{A})$ and $\delta^{13} \mathrm{C}(\mathrm{B})$ of carbonates, temperatures 1192 from carbonate clumped isotope measurements $(C)$, and measured $\delta^{18} \mathrm{O}$ of interstitial water 1193 and calculated $\delta^{18} \mathrm{O}$ of fluids in equilibrium with carbonates from carbonate clumped isotope 1194 analysis (D). Roman numerals show intervals of lithologic units I through V for Site C0011; 1195 SMTZ is depth of sulfate-methane transition zone (Expedition 333 Scientists, 2012b).

1196 Carbonates are keyed to mineralogy by symbol. Circled symbols in A and B denote samples 1197 analyzed for clumped isotopes. Dashed fields highlight carbonates with isotopic signatures 1198 dominated by deeper characteristics. Small gray circles in $\mathrm{B}$ are $\delta^{13} \mathrm{C}$ values of dissolved 1199 inorganic carbon (DIC). Gray fields show expected ranges of isotope signatures for cements 1200 precipitated in equilibrium with seawater-like fluids. Note the preservation of seawater-like $1201 \delta^{18} \mathrm{O}$ values in some of the deeper samples. C. Temperatures of carbonate formation 1202 determined with the clumped isotope method follow the geotherm of Marcaillou et al. (2012).

1203 The geotherm is based on borehole measurements in the upper $180 \mathrm{mbsf}$ and is 1204 extrapolated to depth using core-based measurements of thermal conductivity of the 1205 sediments (Expedition 333 Scientists, 2012b). The clumped carbonate temperatures 1206 generally lie close to the geotherm, with the exception of 3 samples (see text for discussion). 1207 One standard error in temperatures are shown by horizontal lines where larger than symbol. 1208 D. $\delta^{18} \mathrm{O}$ of waters during carbonate formation determined from clumped isotope 1209 temperatures and fractionation expression of Kim and O'Neil (1997) for calcite. Gray circle 1210 shows an example of one possible correction of the oxygen isotope value for a sample that 1211 is $~ 90 \mathrm{wt} \%$ rhodochrosite-siderite (see text for discussion). Gray ovals are $\delta^{18} \mathrm{O}$ values of 1212 interstitial waters squeezed from core samples. The clumped water isotopes are generally 1213 higher than modern IW. Carbonate isotope values are relative to Vienna PeeDee Belemnite 1214 standard (V-PDB); water values are relative to Vienna Standard Mean Ocean Water (V1215 SMOW).

1217 Figure 6. Stable isotope data from Site C0012, with same plots and symbols as in Figure 5.

$1218 \mathrm{~A}$ and $\mathrm{B}$. Lowest three samples are two pelagic mudstones just above basalt, and a calcite 1219 vein in basalt. Circled symbols were analyzed for clumped isotopes. $\delta^{13} \mathrm{C}$ values of 1220 carbonates are more depleted in ${ }^{13} \mathrm{C}$ than expected for equilibrium with DIC, the trends 1221 generally are parallel in Lithologic Units IV and V. C. As with C0011, C0012 clumped 1222 temperatures define a trend that is subparallel to the geothermal gradient; only four samples 
1223 have temperatures within one standard error of the gradient. The deep, low-temperature

1224 sample is $\sim 45 \%$ dolomite consistent with formation early at shallow depths, and then

1225 subsequent burial (see text for discussion). The shallowest sample and three of the four

1226 deepest sediment cement samples have temperatures in excess of the modern gradient and

1227 likely did not precipitate in equilibrium with current temperatures, suggesting slightly warmer

1228 conditions prevailed at a time in the past. D. $\delta^{18} \mathrm{O}$ of waters during carbonate formation

1229 determined from clumped isotope temperatures at Site C0012 are further from equilibrium

1230 for several samples than at C0011. Roman numerals show intervals of Lithologic Units I

1231 through VI for Site C0012 (Expedition 333 Scientists, 2012ab).

1232

1233 Figure 7. Strontium isotope ratios and barium concentrations of pore fluids (black squares)

1234 and carbonates (triangles) from IODP Sites C0011 (A) and C0012 (B). Manganese

1235 concentrations are shown for C0011 and C0012 only. Circled symbols in Sr plots are

1236 samples with clumped isotope measurements. Data for IODP Site U1329 (C) (Cascadia

1237 margin, Joseph et al., 2013a) are included for comparison (see discussion). Strontium

1238 isotopic composition of oceanic crust (Staudigel et al., 1981), ash (Joseph et al., 2013a) and

1239 contemporaneous seawater values (Hess et al., 1986; Veizer et al., 1999) are illustrated for

1240 comparison. Sr isotope data from Joseph et al. (2013ab). In carbonates, barium/calcium

1241 ratios $(\mu \mathrm{mol} / \mathrm{mol}$ ) are measured by ICP-OES, manganese/calcium ratios (wt\% x10/wt\%) by

1242 microprobe.

1243

1244 Figure 8. Plot of carbonate formation temperature compared with $\delta^{18} \mathrm{O}$ values of fluids

1245 calculated using fractionation expression of Kim and O'Neil (1997). $\Delta_{47}$ values corresponding

1246 to temperatures are based on the calibration from Tripati et al. (2015). Dashed lines and per

1247 mil values relative to SMOW of corresponding carbonates are shown with dashed lines.

1248 Moving from left to right represents increasing burial and temperatures. Carbonates formed

1249 under conditions of increasing burial in open marine conditions would plot as a field centered

1250 on $\delta^{18} \mathrm{O}$ equal to $\sim 0 \%$. Carbonate oxygen isotope values are pulled to higher numbers if

1251 heavier waters are released from diagenesis of smectite to illite, represented by "clay-bound

1252 water". Negative $\delta^{18} \mathrm{O}$ values result if heavier oxygen is fractionated into newly formed clays

1253 during alteration of volcanic matter or other reactive silicate minerals. Most carbonates likely

1254 formed from waters dominated by marine isotopes with an important component of lighter

1255 waters from silicate alteration. A few samples with positive $\delta^{18} \mathrm{O}$ values indicate ingress of

1256 clay-bound waters from clay mineral diagenesis. Note there are two samples corrected to

1257 lower $\delta^{18} \mathrm{O}$ values (gray data symbols) because they either are dominated by dolomite ("D";

1258 Sample 333-12D-6H-1, 13-14) or rhodochrosite-siderite (RS; 322-11B-45R-4, 86-88). 
1260 Figure 9. Model of carbonate formation with depth. Upper zone (A) of cementation (gray 1261 layers) contains calcite, Mn-calcite, R-S, and dolomite, indicating reduced manganese and 1262 iron in pore waters. Carbonate is low in barium because of barite precipitation above the 1263 sulfate-methane transition zone. ${ }^{87} \mathrm{Sr} /{ }^{86} \mathrm{Sr}$ and $\delta^{18} \mathrm{O}$ values are high due to seawater1264 dominated pore waters and low temperatures, respectively. Dissolved inorganic carbon was 1265 likely ${ }^{13} \mathrm{C}$ depleted in sulfate-methane transition zone. With increasing burial (B) carbonates 1266 dissolve and locally re-precipitate. At greater depth $(C)$ progressive ash alteration has 1267 lowered ${ }^{87} \mathrm{Sr} /{ }^{86} \mathrm{Sr}$ values in pore waters resulting in somewhat lower strontium isotope ratios 1268 in carbonate. Variations in manganese and higher barium in carbonate reflect pore water 1269 compositions. $\delta^{18} \mathrm{O}$ and carbonate clumped temperatures are consistent with recrystallization 1270 of carbonate cements to approach equilibrium with in situ pore waters. 
TABLE 1. CARBONATE GEOCHEMICAL DATA

\begin{tabular}{|c|c|c|c|c|c|}
\hline $\begin{array}{l}\text { sample } \\
\text { number }\end{array}$ & $\begin{array}{l}\text { depth } \\
\text { (mbsf) }\end{array}$ & $\begin{array}{l}{ }^{18} \mathrm{O} \\
(\%) \dagger\end{array}$ & $\begin{array}{l}\square^{13} \mathrm{C} \\
(\% \circ)\end{array}$ & ${ }^{8 /} \mathrm{Sr} /{ }^{86} \mathrm{Sr}$ & $\begin{array}{c}\mathrm{Ba} / \mathrm{Ca} \\
(\mathrm{mmol} / \mathrm{mol})\end{array}$ \\
\hline \multicolumn{6}{|l|}{ C0011B- } \\
\hline$\overline{8 R 7,34-36}$ & 422.19 & -1.89 & -3.91 & 0.708086 & 13.8 \\
\hline $8 R 7,66-68$ & 422.41 & -7.03 & -20.14 & 0.708507 & 0.6 \\
\hline 12R3 102-104 & 444.02 & & & 0.708351 & 5.5 \\
\hline 13R5, 73.5-77.5 & 455.82 & -3.43 & -2.58 & 0.707774 & 3.3 \\
\hline 14R1, 47-49 & 460.47 & -0.17 & -18.47 & 0.708468 & 0.3 \\
\hline 32R1, 107.5-109 & 597.00 & -6.78 & -13.59 & & \\
\hline 32R1, 122-123.5 & 597.15 & -0.95 & -21.56 & 0.708692 & 1.7 \\
\hline $33 R 3,57-58$ & 607.05 & -4.74 & -23.36 & 0.708560 & 0.8 \\
\hline 33R4, 50-51 & 608.75 & -3.40 & -7.05 & 0.707785 & 4.7 \\
\hline $33 R 5,65-67$ & 610.40 & 1.65 & -12.58 & 0.708534 & 3.7 \\
\hline $38 R 6,17-19$ & 659.34 & -0.43 & -10.54 & 0.708126 & 5.4 \\
\hline $39 R 2,39-41$ & 664.22 & -6.40 & -15.21 & 0.708503 & 0.6 \\
\hline 41RCC, 5-7 & 678.60 & -6.06 & -20.67 & 0.708480 & 0.8 \\
\hline $45 R 1,54-56$ & 699.04 & -1.83 & -6.93 & & \\
\hline $45 R 4,86-88$ & 701.67 & -1.87 & -10.07 & 0.708237 & 2.2 \\
\hline $48 R 2,21-22$ & 722.21 & -0.30 & -7.45 & 0.708179 & 4.8 \\
\hline 50R2, 45-46 & 739.25 & -3.36 & -7.02 & & \\
\hline 50R3, 31-32 & 740.61 & -2.22 & -5.93 & 0.708463 & 1.2 \\
\hline $51 R 1,107-108$ & 748.47 & -11.88 & -11.25 & & \\
\hline $51 R 3,29-31$ & 750.54 & -10.34 & -11.49 & 0.707910 & 0.1 \\
\hline 51R6, 92-94 & 754.43 & -0.97 & -6.84 & 0.708408 & 3.4 \\
\hline 51R7, 15.5-16 & 753.74 & 1.27 & -10.21 & 0.708555 & 1.3 \\
\hline 52R5, 33-35 & 762.56 & -9.94 & -8.78 & 0.708456 & 0.4 \\
\hline 57R3, 73-75 & 849.67 & -10.46 & -14.43 & & \\
\hline 59R1, 111-113 & 865.64 & -11.86 & -19.66 & & \\
\hline \multicolumn{6}{|l|}{ C0011D- } \\
\hline$\overline{11 \mathrm{H} 8,95}-96$ & 108.31 & -0.73 & -0.25 & & \\
\hline $13 H 7,11-12$ & 125.34 & -0.60 & 0.34 & & \\
\hline $26 \times 2,58-59$ & 206.43 & -1.10 & -2.55 & & \\
\hline $27 \times 5,127-128$ & 214.48 & -1.48 & -0.16 & & \\
\hline $29 \times 2,112-113$ & 222.32 & -2.60 & 0.26 & & \\
\hline $30 \times 3,125-127$ & 228.88 & -1.31 & -0.93 & & \\
\hline $31 \times 1,69-70$ & 242.19 & -1.08 & -2.03 & & \\
\hline $31 \times 5,97-98$ & 239.42 & -1.60 & -0.93 & & \\
\hline $33 \times 4,64-65$ & 249.81 & -0.66 & -1.11 & & \\
\hline $34 \times 1,65-66$ & 252.15 & -2.72 & -0.52 & & \\
\hline $36 \times 3,64-65$ & 269.47 & 0.50 & -3.42 & & \\
\hline $37 \times 2,11-12$ & 276.99 & -1.82 & -3.21 & & \\
\hline $38 \times 6,72-73$ & 288.40 & -1.43 & -2.07 & & \\
\hline $39 \times 3,96-97$ & 295.77 & -1.44 & -2.48 & & \\
\hline $40 \times 7,83-84$ & 309.20 & -1.38 & -2.15 & & \\
\hline $41 \times 7,82-83$ & 319.01 & -0.58 & -1.41 & & \\
\hline \multicolumn{6}{|l|}{ C0012A- } \\
\hline$\overline{12 \mathrm{R} 2,43}-44$ & 150.86 & 3.98 & -13.18 & & \\
\hline $16 R 1,5-7$ & 188.95 & -3.53 & -17.23 & 0.708182 & 0.6 \\
\hline 20R1, 73-74 & 225.23 & 3.10 & -13.34 & 0.708553 & 0.8 \\
\hline 20R4, 118-119 & 230.18 & 3.72 & -12.18 & 0.708293 & 1.5 \\
\hline 31R4, 103-105 & 332.10 & -4.75 & -15.60 & 0.708391 & 1.0 \\
\hline $32 R 1,73-76$ & 339.40 & -7.44 & -19.51 & 0.708135 & 0.2 \\
\hline $34 R 1,129-131$ & 358.29 & -9.40 & -15.65 & 0.707922 & 0.5 \\
\hline 36R3, 48-50 & 378.15 & -8.61 & -17.45 & 0.708337 & 0.3 \\
\hline $39 R 4,6-8$ & 408.44 & -2.56 & -13.22 & 0.707991 & 1.5 \\
\hline $40 R 6,11-22$ & 419.86 & -11.40 & -16.74 & & \\
\hline $41 R C C, 12-13$ & 429.75 & -12.23 & -18.72 & 0.707264 & 0.1 \\
\hline $46 R C C, 36-40$ & 474.44 & -11.34 & -22.48 & 0.707149 & 1.7 \\
\hline 47R2, 30-35 & 481.07 & -3.56 & -0.65 & & \\
\hline \multicolumn{6}{|l|}{ C0012C- } \\
\hline$\overline{7 \mathrm{H} 4,124}-125$ & 55.85 & -1.91 & -0.32 & & \\
\hline
\end{tabular}




\begin{tabular}{|c|c|c|c|}
\hline $8 H 8,47-48$ & 69.17 & -0.97 & -0.10 \\
\hline $11 \mathrm{H} 5,24-25$ & 91.42 & -0.22 & -2.01 \\
\hline $12 \mathrm{H} 3,76-77$ & 97.59 & -3.39 & -2.44 \\
\hline $\begin{array}{l}15 \mathrm{H} 7,46-47 \\
\mathrm{C} 0012 \mathrm{D}-\end{array}$ & 123.49 & -0.50 & -0.96 \\
\hline $2 \mathrm{2H} 8,30-31$ & 125.18 & -1.38 & -0.47 \\
\hline $4 \mathrm{H} 1,84-85$ & 134.84 & -2.02 & -2.23 \\
\hline $4 \mathrm{H} 5,81-82$ & 139.07 & -6.84 & -10.61 \\
\hline $6 \mathrm{H1}, 13-14$ & 146.63 & 5.70 & -11.19 \\
\hline $6 \mathrm{H} 3,8-9$ & 149.41 & 0.53 & -7.20 \\
\hline $6 \mathrm{H} 5,14-15$ & 149.96 & 1.23 & -8.67 \\
\hline $11 \mathrm{H} 5,16-17$ & 172.80 & -2.83 & -6.70 \\
\hline $11 \mathrm{H} 5,58-59$ & 173.22 & -3.46 & -6.29 \\
\hline $11 \mathrm{H} 5,95-96$ & 173.59 & -3.15 & -4.18 \\
\hline $11 \mathrm{H} 5,110-111$ & 173.75 & -1.24 & -4.75 \\
\hline $13 \mathrm{H} 5,48-49$ & 180.50 & -1.60 & -1.78 \\
\hline $\begin{array}{l}13 \mathrm{H} 5,71-72 \\
\mathrm{C} 0012 \mathrm{E}-\end{array}$ & 180.90 & -3.20 & -17.03 \\
\hline $\begin{array}{l}3 \times 8,57-58 \\
\text { C0012G- }\end{array}$ & 526.67 & -15.96 & -8.78 \\
\hline $\begin{array}{l}\text { 1R1, 44-45 } \\
1 \mathrm{R} 1,51-52\end{array}$ & $\begin{array}{l}515.44 \\
515.51\end{array}$ & $\begin{array}{l}-4.23 \\
-2.20\end{array}$ & $\begin{array}{l}-0.10 \\
0.09\end{array}$ \\
\hline $\begin{array}{l}\text { Note: Holes C0011B } \\
\text { C0012D, C0012E, a } \\
\text { Sample numbers in } \\
{ }^{*} \text { Permil values vs. V } \\
t^{87} \mathrm{Sr} r^{86} \mathrm{Sr} \text { data norm } \\
\text { reported }{ }^{87} \mathrm{Sr} r^{86} \mathrm{Sr} \text { va } \\
\text { 91) was obtained for } \\
\text { not determined. } \\
\text { §N.D. = not determir }\end{array}$ & $\begin{array}{l}\text { have } \\
\text { PeeDe } \\
\text { d to Nati } \\
\text { f } 0.7102 \\
\text { ated me }\end{array}$ & $\begin{array}{l}\text { nate cli } \\
\text { lemnite } \\
\text { I Bureal } \\
\text { A mean } \\
\text { rement }\end{array}$ & $\begin{array}{l}\text { IODP Expedition 322; Holes C0011D, } \\
\text { DP Expedition } 333 \text {. } \\
\text { ved isotope data presented in Table } 2 \text {. } \\
\text { andard. } \\
\text { Standards standard NBS } 987, \text { with a } \\
\text { lue of } 0.710225 \pm 0.000052(2 \sigma \text { mean; } n= \\
\text { trontium concentrations in carbonates were }\end{array}$ \\
\hline
\end{tabular}


TABLE 2. CARBONATE CLUMPED ISOTOPE DATA

\begin{tabular}{|c|c|c|c|c|c|c|c|c|c|c|c|c|}
\hline Sample number & $\mathrm{n}=$ & $\begin{array}{c}\text { पिमान } \\
\text { (mbsf) }\end{array}$ & $\begin{array}{c}\delta^{13} \mathrm{C} \\
\text { mineral } \\
(\%)^{1}\end{array}$ & $\begin{array}{c}\delta^{13} \mathrm{C} \\
1 \text { s.e. }\end{array}$ & $\begin{array}{c}\delta^{18} \mathrm{O} \\
\text { mineral } \\
(\%)(\%)\end{array}$ & $\begin{array}{l}\delta^{18} \mathrm{O} \\
1 \text { s.e. }\end{array}$ & $\begin{array}{l}\Delta_{47}^{*} \\
(\% \circ)\end{array}$ & $\begin{array}{c}\Delta 47 \\
1 \text { s.e. }\end{array}$ & $\begin{array}{l}\Delta_{47} \mathrm{~T} \\
\left({ }^{\circ} \mathrm{C}\right)^{2}\end{array}$ & $\begin{array}{l}\mathrm{T}\left({ }^{\circ} \mathrm{C}\right) \\
1 \text { s.e. }\end{array}$ & $\begin{array}{l}\text { Water } \\
\delta^{18} \mathrm{O} \\
(\% 0)^{3}\end{array}$ & $\begin{array}{l}\text { Water } \\
\delta^{18} \mathrm{O} \\
\text { 1. s.e. }\end{array}$ \\
\hline \multicolumn{13}{|l|}{ C0011B- } \\
\hline $8 R 7,66-68$ & 3 & 422.41 & -20.127 & 0.008 & -6.439 & 0.013 & 0.650 & 0.003 & 35 & 1.0 & -2.1 & 0.2 \\
\hline $33 R 3,57-58$ & 8 & 607.05 & -23.466 & 0.038 & -3.913 & 0.016 & 0.633 & 0.009 & 40 & 2.8 & 1.4 & 0.5 \\
\hline 39R2 39-41 & 2 & 664.22 & -14.541 & 0.015 & -6.323 & 0.160 & 0.645 & 0.011 & 37 & 3.2 & -1.7 & 0.8 \\
\hline $45 R 4,86-88$ & 1 & 701.67 & -10.191 & 0.004 & -2.207 & 0.014 & 0.631 & 0.010 & 41 & 3.2 & 3.2 & 0.6 \\
\hline 51R1, 107-108 & 2 & 748.47 & -10.668 & 0.004 & -11.517 & 0.057 & 0.583 & 0.015 & 57 & 5.5 & -3.4 & 1.0 \\
\hline 51R3, 29-31 & 2 & 750.54 & -10.836 & 0.071 & -9.993 & 0.178 & 0.565 & 0.028 & 63 & 10.5 & -0.8 & 1.9 \\
\hline 52R5 33-35 & 2 & 762.56 & -8.614 & 0.042 & -10.330 & 0.094 & 0.571 & 0.012 & 61 & 4.4 & -1.5 & 0.8 \\
\hline \multicolumn{13}{|l|}{ C0011D } \\
\hline $13 \mathrm{H} 7,11-12$ & 2 & 125.34 & 0.318 & 0.035 & -0.154 & 0.006 & 0.720 & 0.037 & 17 & 9.0 & 0.5 & 1.9 \\
\hline $33 \times 4,64-65$ & 5 & 249.81 & -1.578 & 0.624 & 0.083 & 0.156 & 0.722 & 0.009 & 16 & 2.2 & 0.7 & 0.6 \\
\hline \multicolumn{12}{|l|}{ C0012A- } & 1.8 \\
\hline 16R1, 5-7 & 5 & 188.95 & -16.579 & 0.014 & -3.169 & 0.122 & 0.670 & 0.015 & 30 & 4.1 & 0.1 & 0.9 \\
\hline 32R1, 73-76 & 1 & 339.40 & -18.922 & 0.007 & -8.011 & 0.012 & 0.616 & 0.010 & 45 & 3.3 & -1.8 & 0.6 \\
\hline $34 \mathrm{R} 1,129-131$ & 2 & 358.29 & -16.028 & 0.046 & -7.220 & 0.068 & 0.611 & 0.007 & 47 & 2.3 & -0.7 & 0.5 \\
\hline 40R6, 11-12 & 1 & 419.86 & -16.098 & 0.006 & -11.589 & 0.005 & 0.568 & 0.009 & 62 & 3.2 & -2.6 & 0.5 \\
\hline $41 \mathrm{RCC}, 12-13$ & 2 & 429.75 & -19.631 & 0.157 & -11.845 & 0.777 & 0.576 & 0.007 & 59 & 2.5 & -3.3 & 1.2 \\
\hline 46RCC, $36-40$ & 1 & 474.44 & -22.390 & 0.007 & -10.077 & 0.011 & 0.551 & 0.012 & 68 & 4.6 & -0.1 & 0.7 \\
\hline 47R2, 30-35 & 1 & 481.07 & -1.179 & 0.009 & -2.540 & 0.025 & 0.754 & 0.035 & 8.7 & 7.7 & -3.6 & 1.8 \\
\hline \multicolumn{13}{|l|}{ C0012C- } \\
\hline $\begin{array}{l}8 \mathrm{H} 8,47-48 \\
\text { Co012D- }\end{array}$ & 2 & 69.16 & 0.003 & 0.117 & -0.011 & 0.060 & 0.707 & 0.017 & 20 & 4.3 & 1.3 & 1.0 \\
\hline $6 \mathrm{H} 1,13-14$ & 2 & 146.63 & -11.354 & 0.036 & 4.332 & 0.197 & 0.722 & 0.024 & 16 & 5.8 & 4.9 & 1.4 \\
\hline \multicolumn{13}{|l|}{ C0012E- } \\
\hline $3 \times 8,56-57$ & 4 & 526.67 & -9.158 & 0.279 & -12.941 & 0.296 & 0.589 & 0.009 & 54 & 3.2 & -5.2 & 0.8 \\
\hline
\end{tabular}

. Average of temperatures are shown in figure 4.

*absolute reference frame (ARF) corrected value

1 Mineral $\delta^{18} \mathrm{O}$ and $\delta^{13} \mathrm{C}$ relative to Vienna PeeDee Belemnite standard.

2 Temperature and calculated water $\delta^{18} \mathrm{O}$ values are means of replicates using calibration of Tripati et al. (2015)

3 All $\delta^{18} \mathrm{O}$ of water relative to Vienna Mean Standard Ocean Water standard. Values calculated from clumped-isotope temperatures using fractionation expression for calcite (Kim and O'Neil, 1997) without correction for other carbonate phases.

4 Calculated based on standard error of temperatures and carbonate $\delta^{18} \mathrm{O}$ values. 
Figure 1. Location map

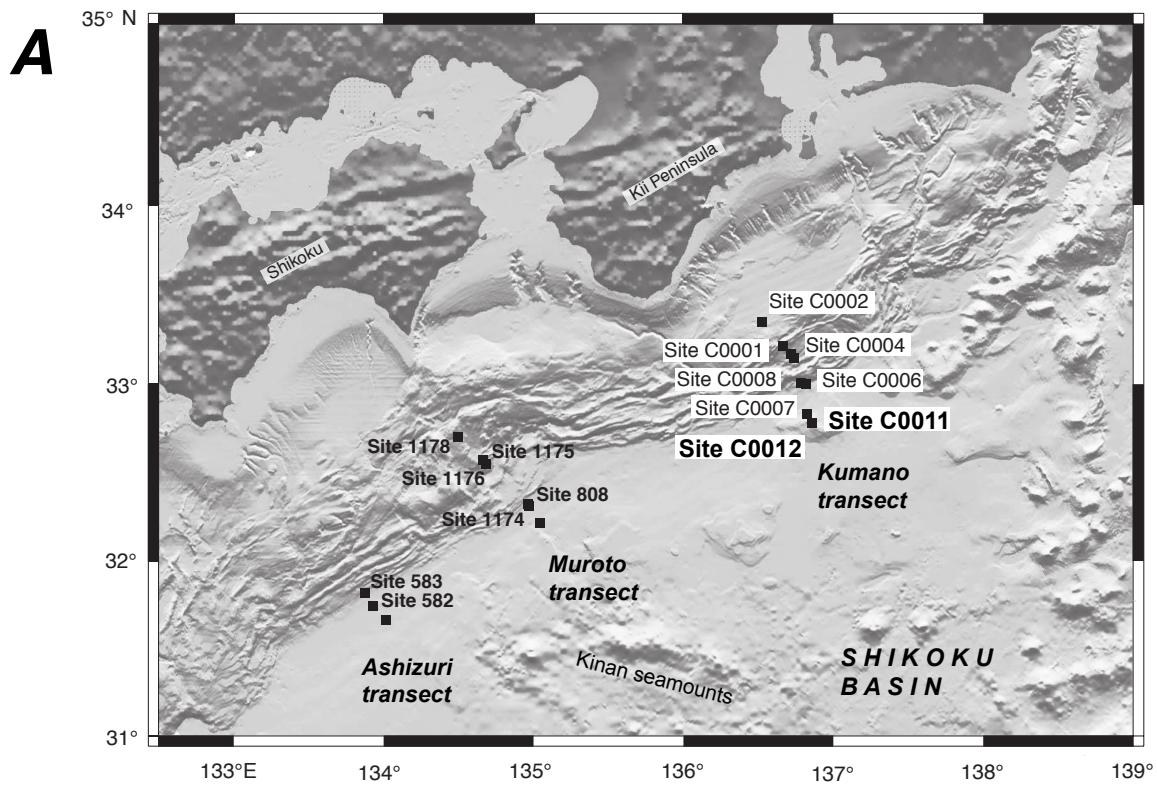

B

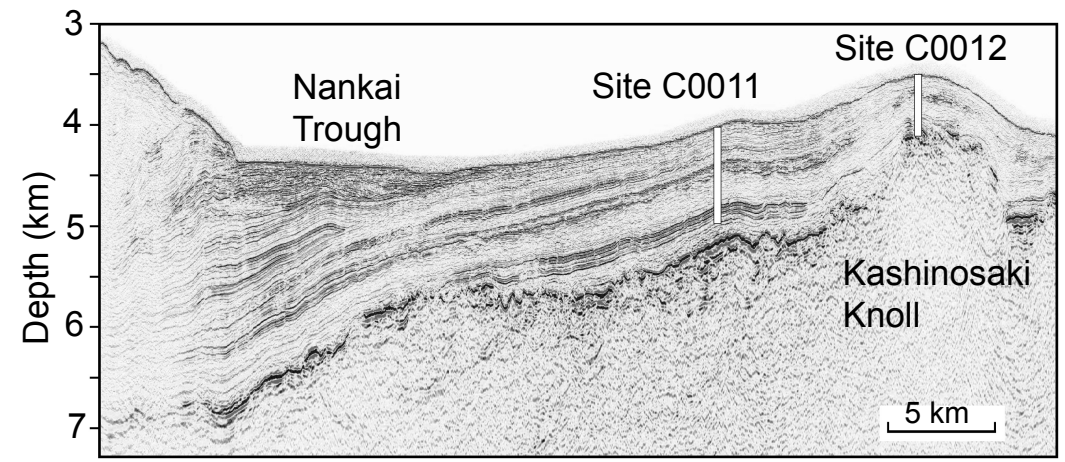

C
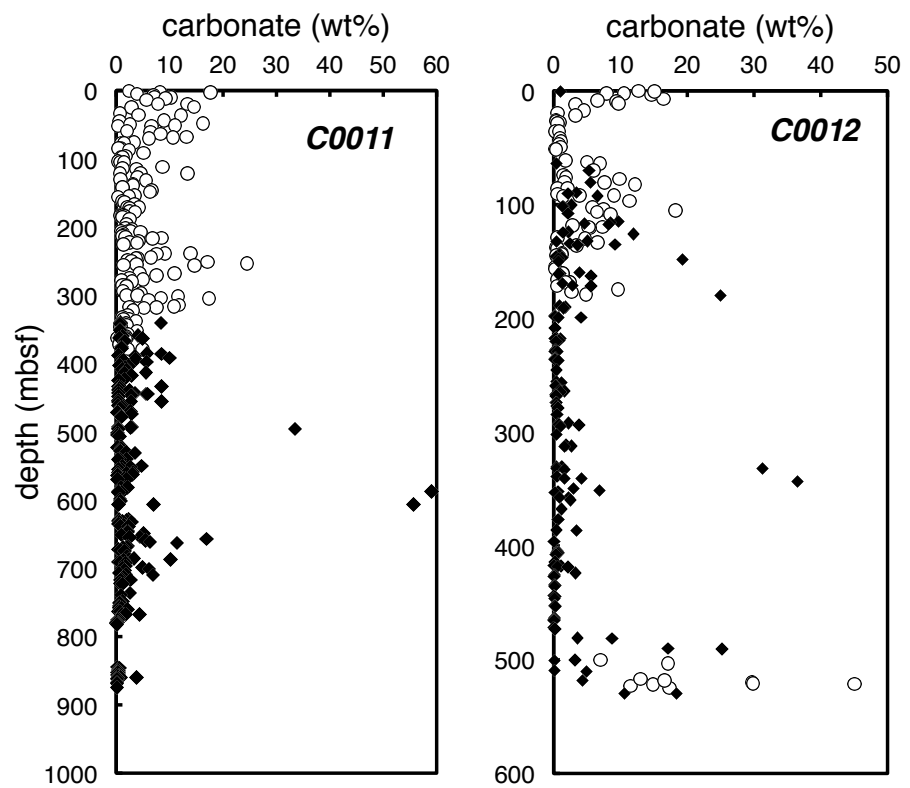

Sample et al. Figure 1 


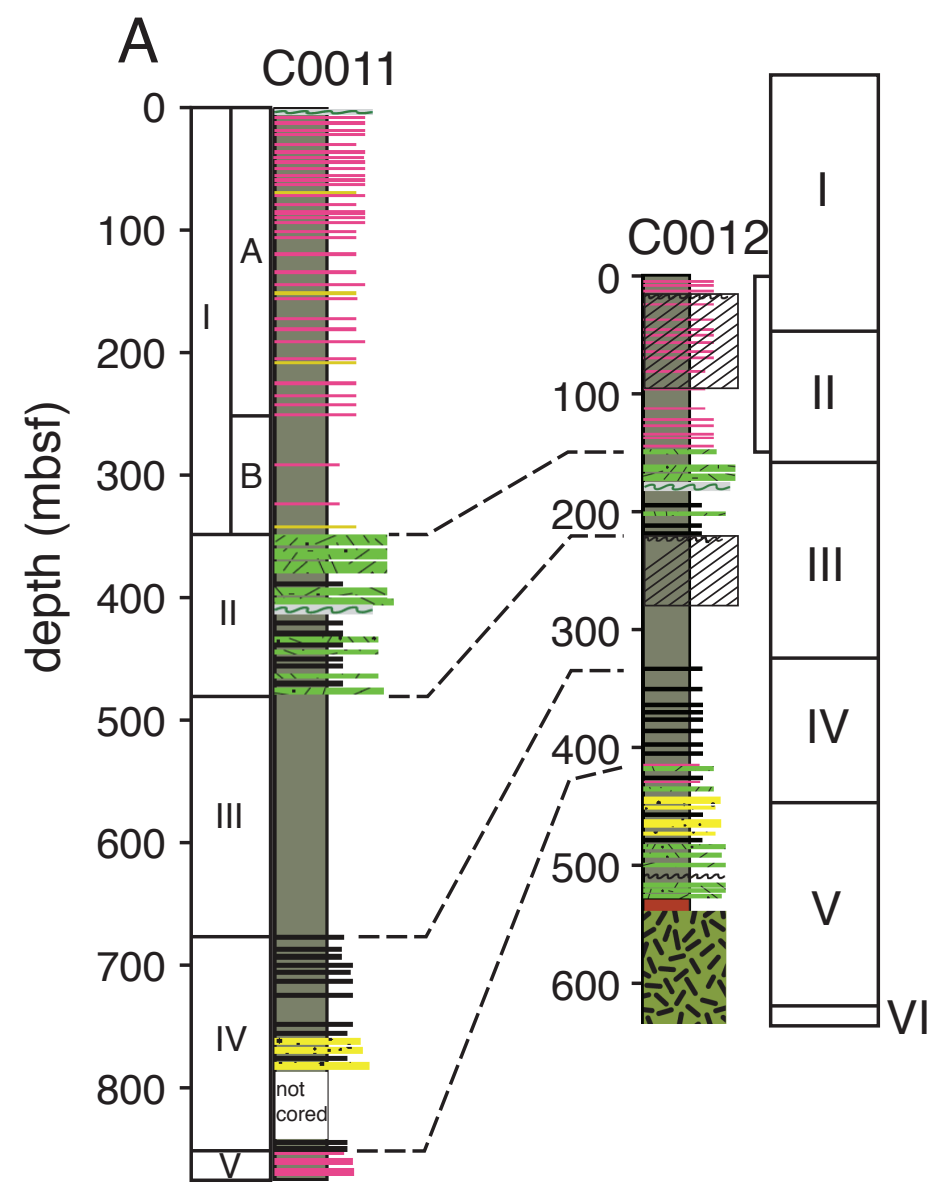

B

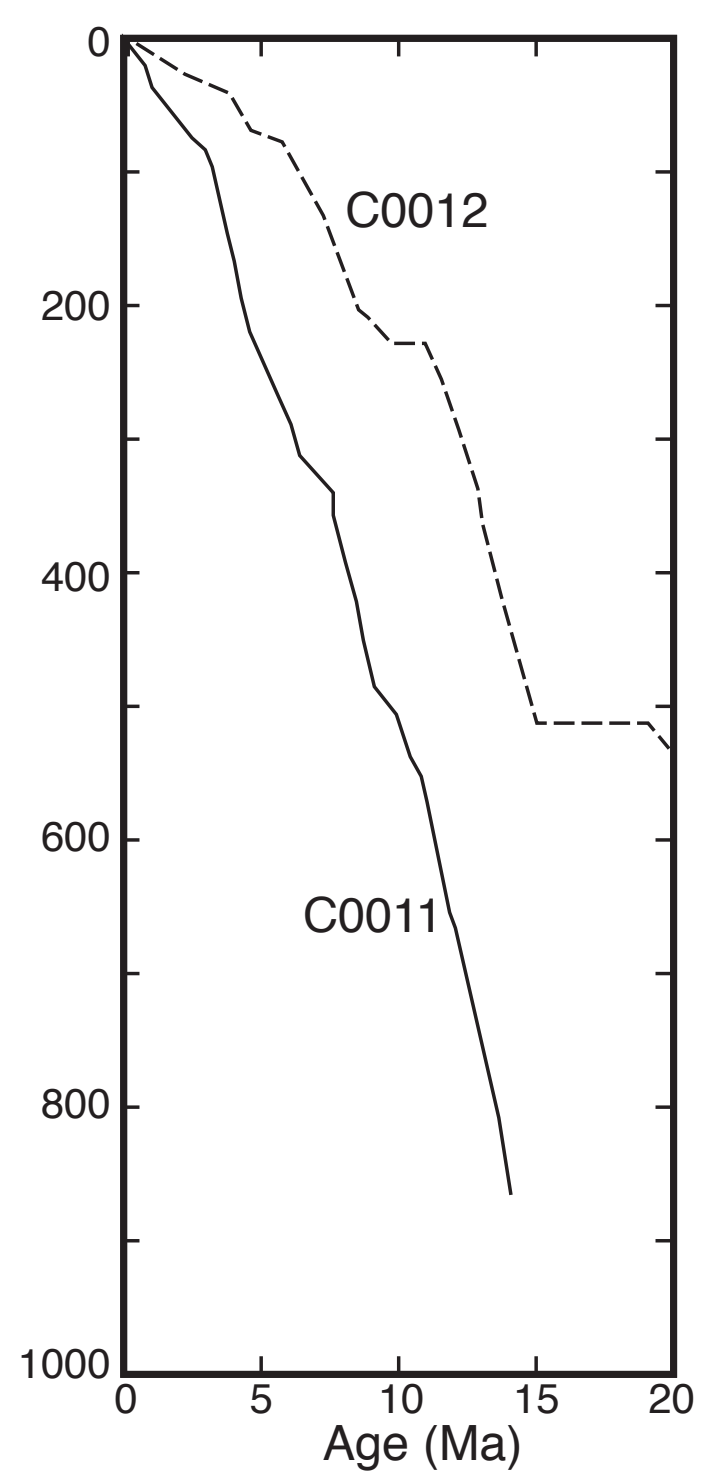

Sample et al. Figure 2

B 

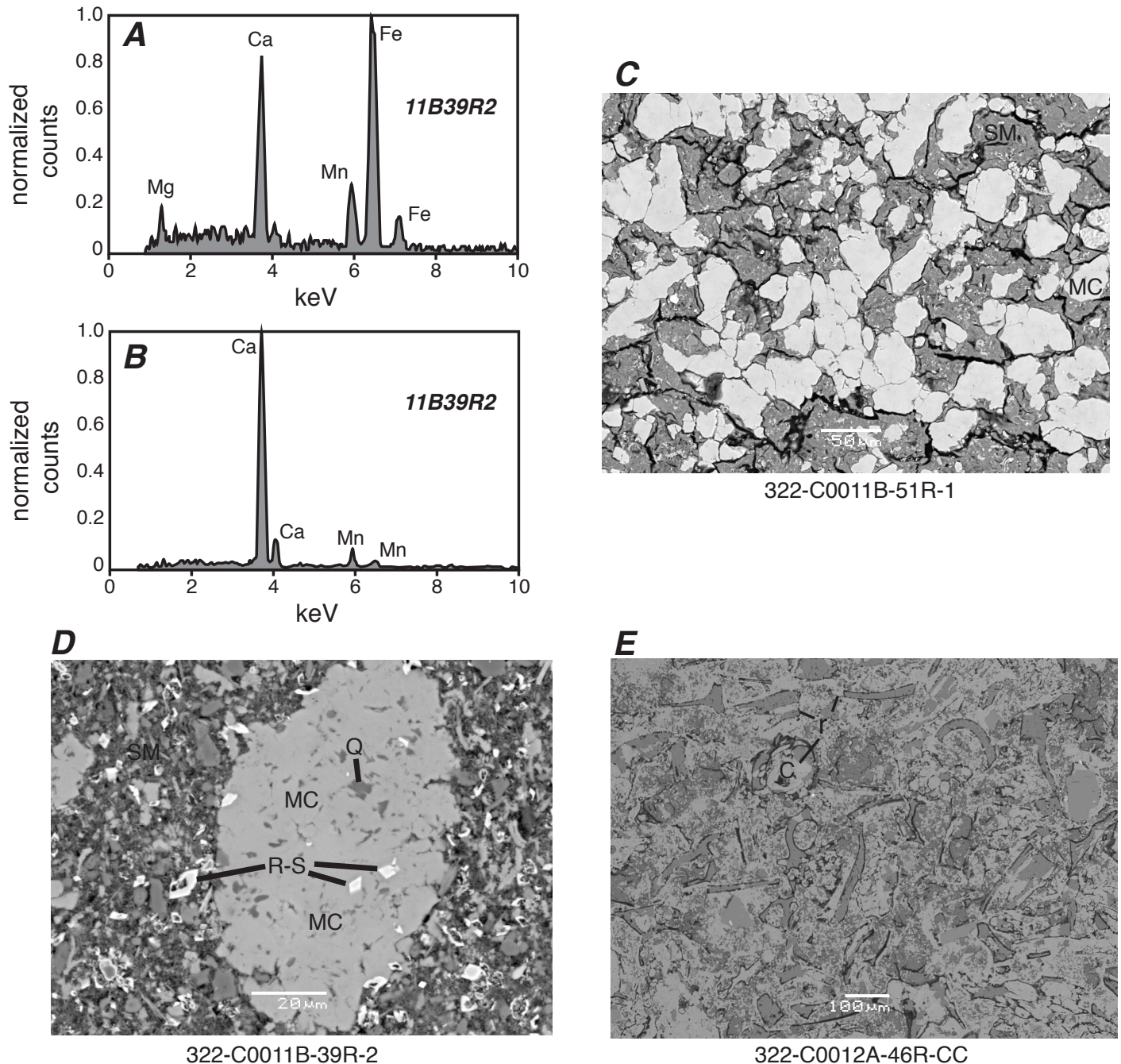

Sample et al. Figure 3 
Figure 4. EPMA mineralogy

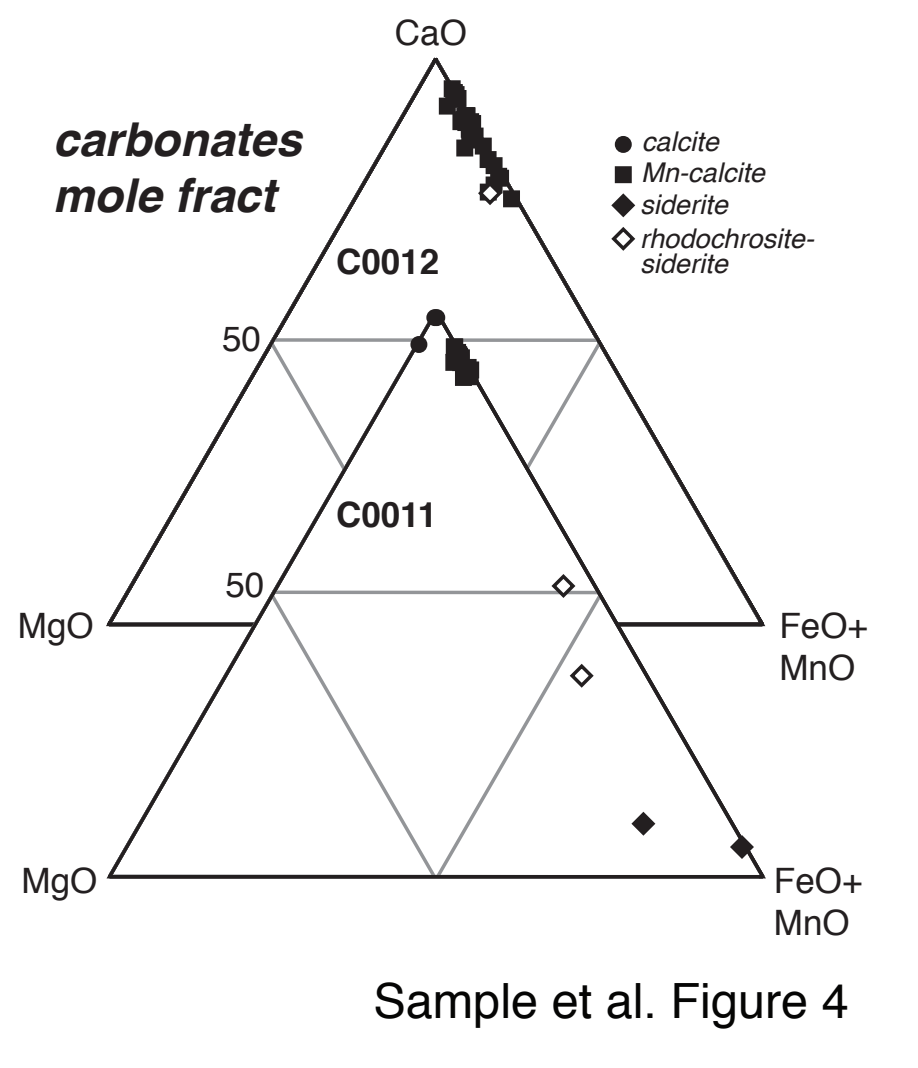

Sample et al. Figure 4

carbonates

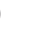

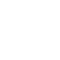

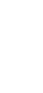
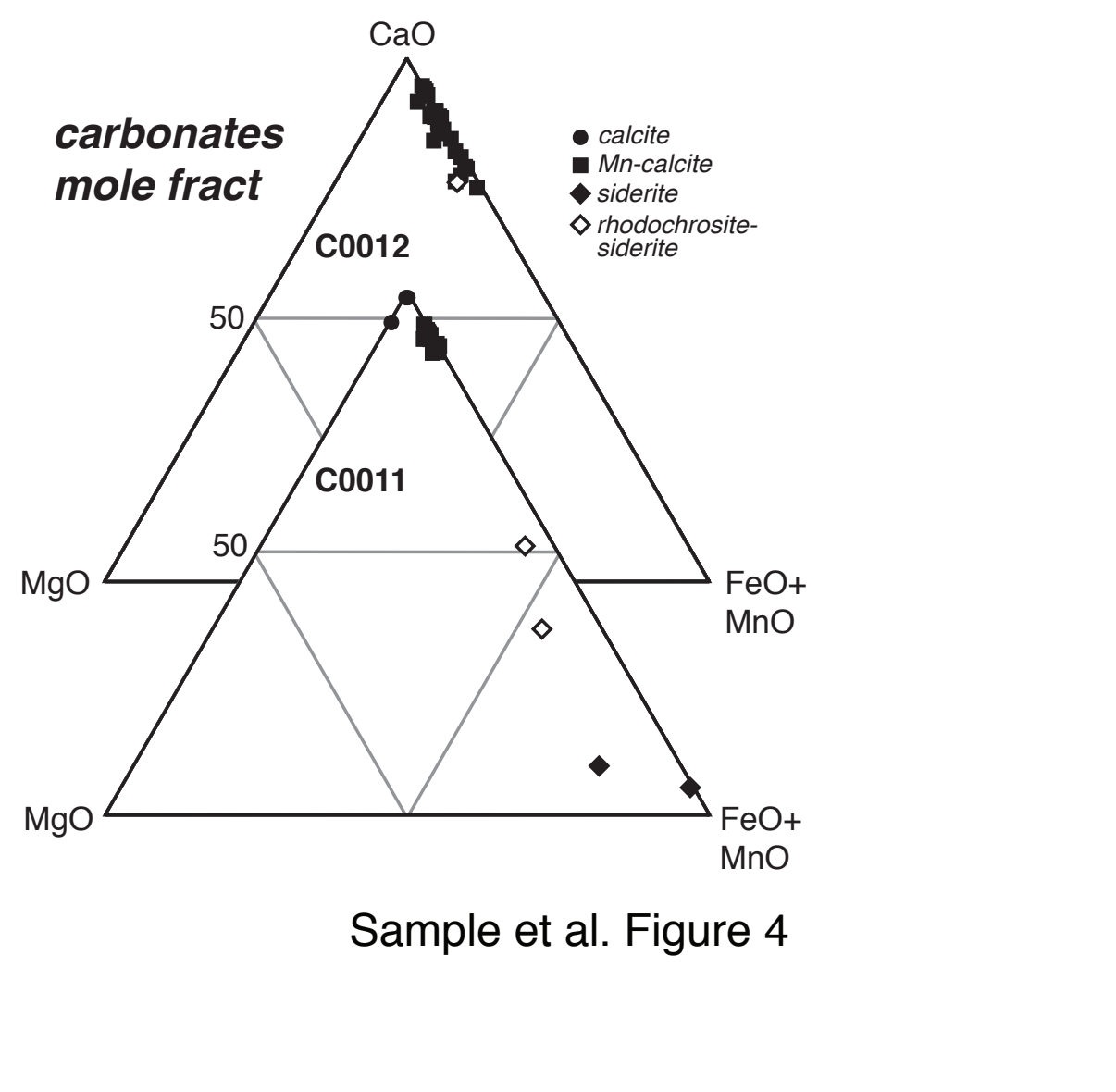


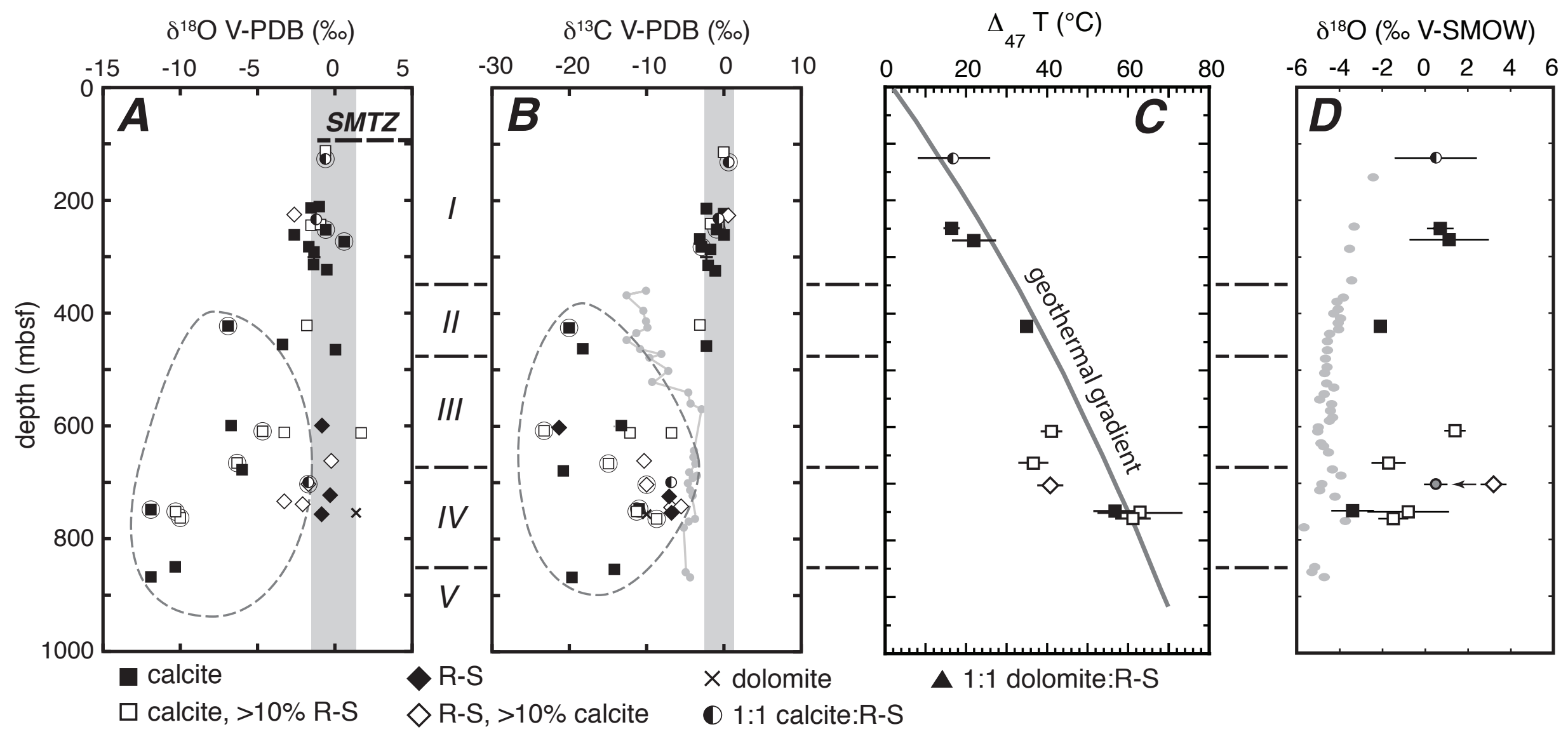

Sample et al. Figure 5 


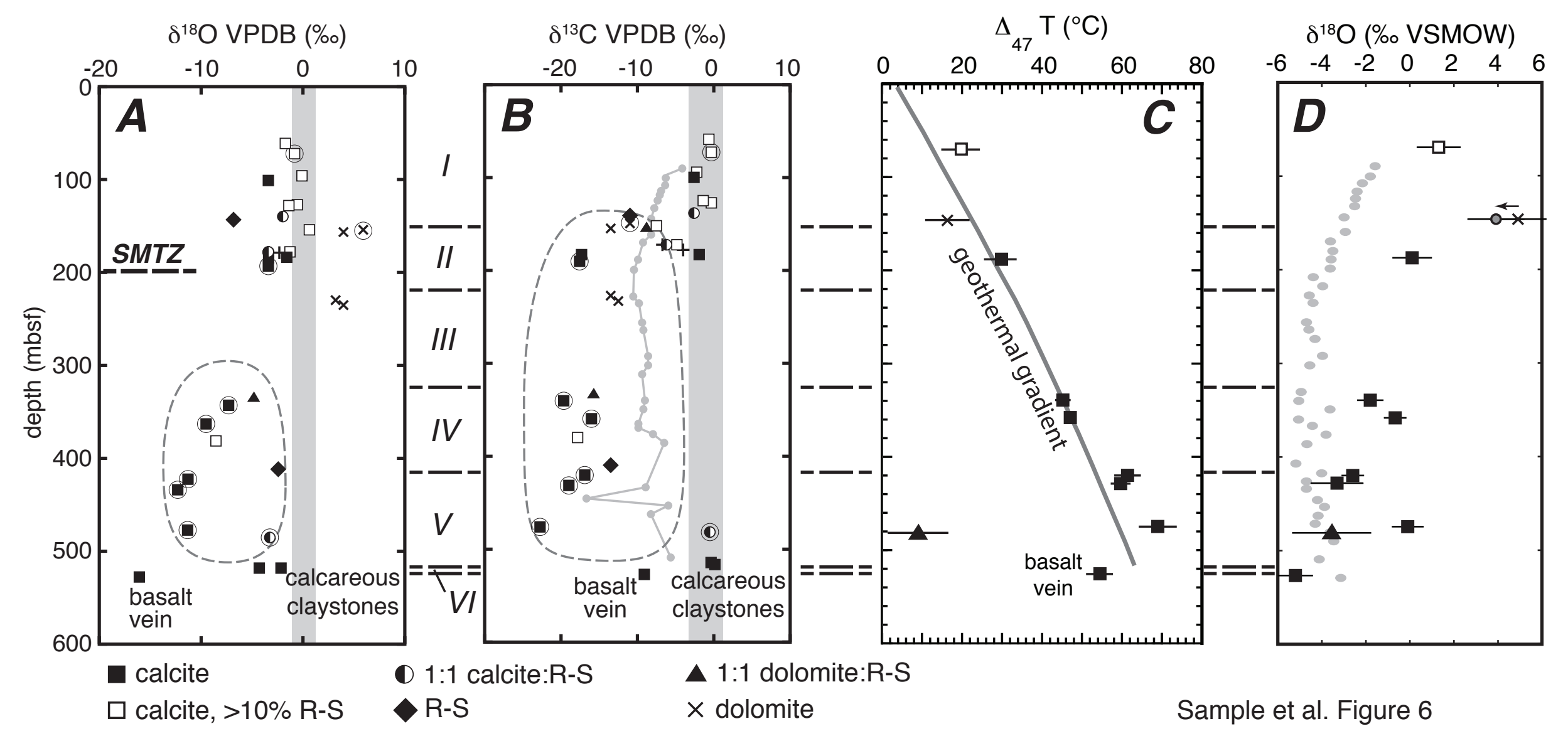




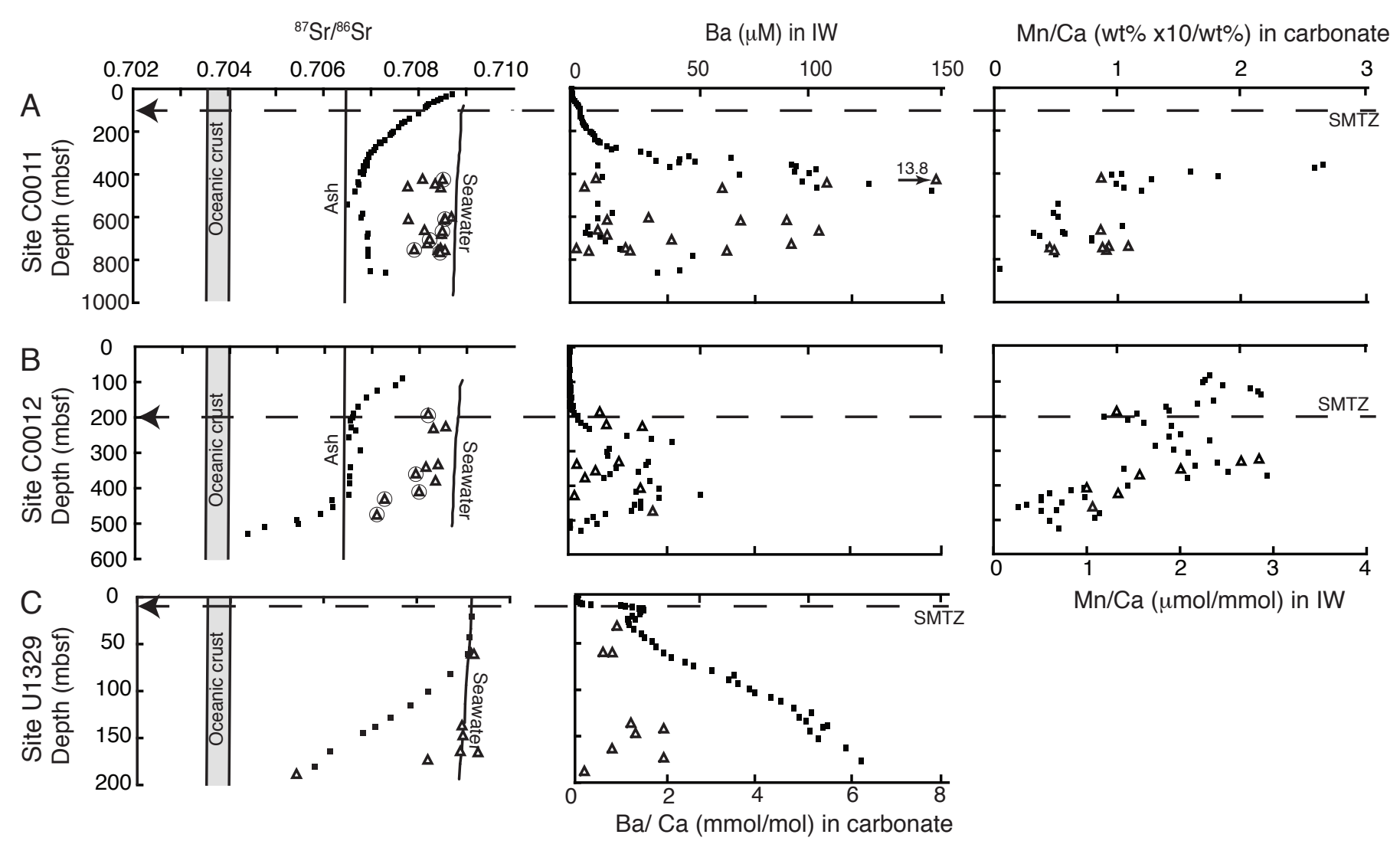

Sample et al. Figure 7 


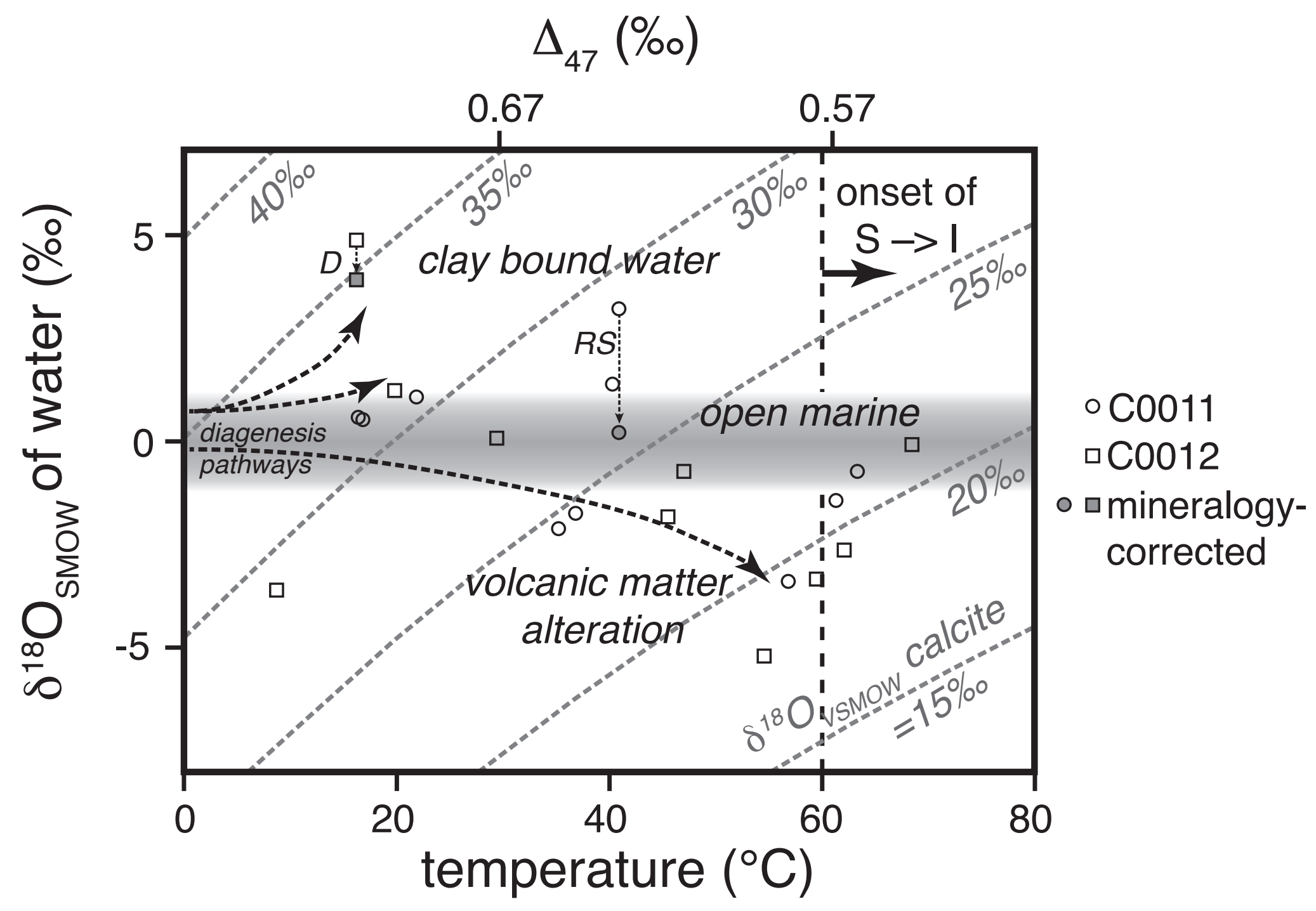

Sample et al. Figure 8 
Figure 9. Summary figure

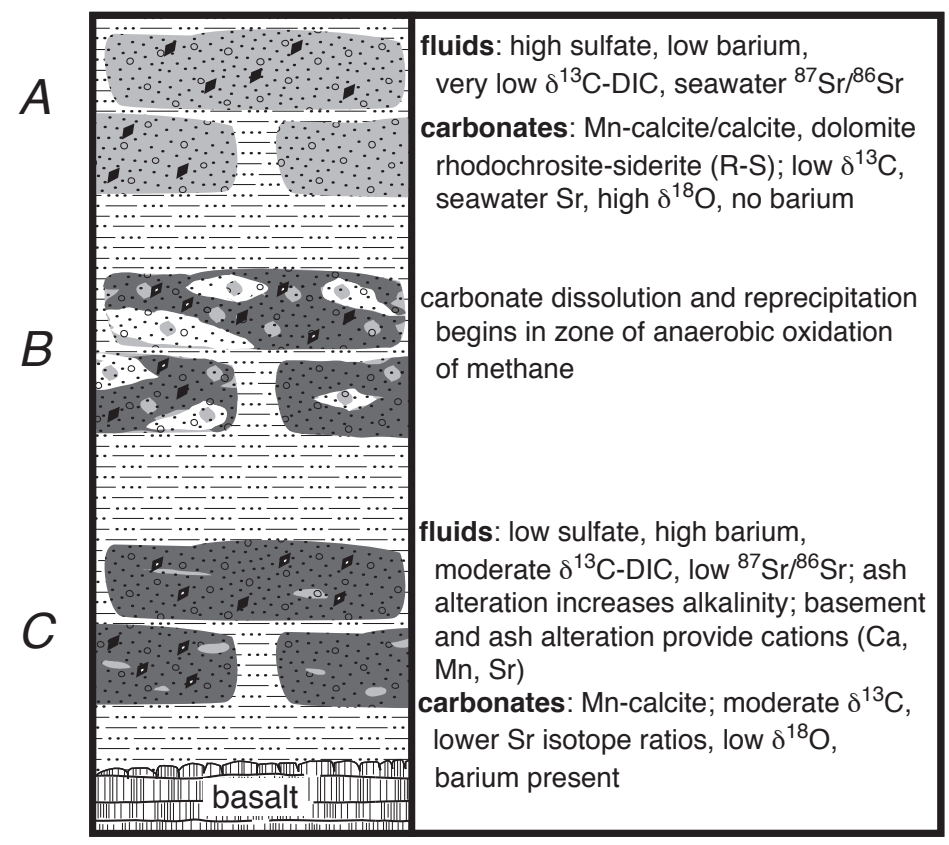

Sample et al Figure 9 